\author{
Florens Felten \\ Claus Reinholdt \\ Eduard Pollhammer \\ Walter Gauß \\ Rudolfine Smetana
}

\title{
Ägina-Kolonna 2007 \\ Vorbericht über die Grabungen des Fachbereichs \\ Altertumswissenschaften/Klassische und Frühägäische Archäologie der Universität Salzburg
}

\section{Einleitung}

Die Arbeiten der Kampagne des Jahres $2007^{1}$ betrafen den Westkomplex (Südbau: Westraum, Westannex II; Norderweiterung: Nordbau, Nordostbau, Nordstraße), stratigraphische Untersuchungen im Bereich >Südhügelく sowie Restaurierungsarbeiten an den prähistorischen Befestigungen nördlich des Apollontempels.

\section{Westkomplex (Abb. 1)}

\section{a. Südbau}

\section{Westraum}

Mit der in der Kampagne 2006 abgeschlossenen Untersuchung des Ostraumes hatte sich für das Areal unter dem Südbau das Gesamtbild einer sepulkralen Nutzung während der Frühen Eisenzeit vervollständigen lassen. Neben den hier festgestellten, in prähistorische Strukturen eingetieften, protogeometrischen Bestattungen belegten insbesondere die zwei aufrecht stehenden Steinmale (>grave-marker`) sowie die bereits 2003 unter dem Kernbau angetroffenen, runden Steinplattformen die rituellen Bezüge des gesamten Befundes. Ferner hatte sich gezeigt, dass bei der Errichtung der spätarchaischen Anlage des Südbaus auf die augenscheinlich noch sichtbaren Steinmale besondere Rücksicht genommen worden war. Die Bestattungen selbst waren bereits im Zuge einer vorerrichtungszeitlichen Planierung des Geländes stark in Mitleidenschaft gezogen worden.

\footnotetext{
${ }^{1}$ Gesamtleitung der Arbeiten: F. Felten; Grabungsleitung Westkomplex: C. Reinholdt; Grabungsleitung Südhügel: R. Smetana, W. Gauß, G. Klebinder-Gauß; Photographie und Layout: M. Del-Negro, C. Reinholdt, W. Gauß, R. Smetana; Architekturaufnahme: E. Pollhammer; Mitarbeiterinnen Architekturaufnahme: D. Leiner, V. Leitner, G. Schmidhuber; Fundverwaltung, Koordination und Museumsarbeiten: V. Felten; Mitarbeiter/innen: P. Eitzinger, J. Krämmer, A. Kurz, A. Paule, M. Stütz, S. Tischler; Fundrestaurierung: T. Zikou, B. Schneider; Projektarbeiten: V. Jarosch-Reinholdt: Geometrische Keramik; G. Klebinder-Gauß: Schwarzfirnis- und Küchenware; M. Lindblom: Keramik der Mittleren Bronzezeit; L. Berger: FH II-Keramik; E. Pollhammer: Historische Bausubstanz und Architekturglieder; K. Pruckner: Frühmykenische Keramik; Finanzierung: Paris-Lodron-Universität Salzburg, Fonds zur Förderung der Wissenschaftlichen Forschung (Wien), Institute of Aegean Prehistory (Philadelphia), Dr. G. Schuhfried (Mödling), Dr. H. Wiesmüller (Salzburg). Die Unterzeichneten danken Dr. E. Ligouri und E. Papastavrou, K $\Sigma T$ Ephorie für Prähistorische und Klassische Altertümer (Piräus), für freundliche Unterstützung; zu den früheren Kampagnen vgl. F. Felten u. a., Ägina-Kolonna 2002, ÖJh 72, 2003, 41-65; F. Felten u. a., Ägina-Kolonna 2003, ÖJh 73, 2004, 97-128; F. Felten u. a., Ägina-Kolonna 2004, ÖJh 74, 2005, 7-37; F. Felten u. a., Ägina-Kolonna 2005, ÖJh 75, 2006, 9-38; F. Felten u. a., Ägina-Kolonna 2006, ÖJh 76, 2007, 89-119.
} 


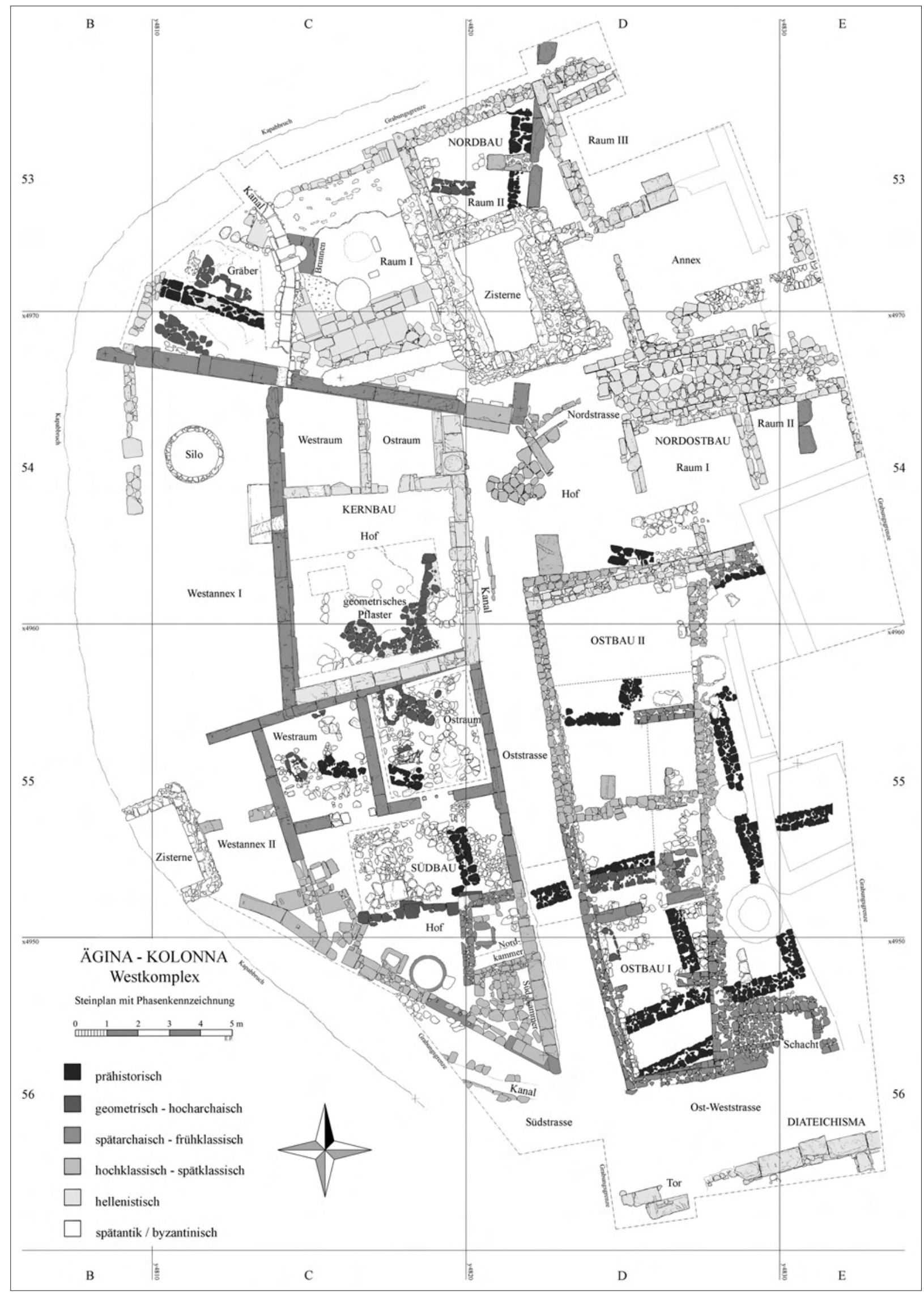

1 Westkomplex. Gesamtplan B-E/53-56 mit Phasenkennzeichnung 


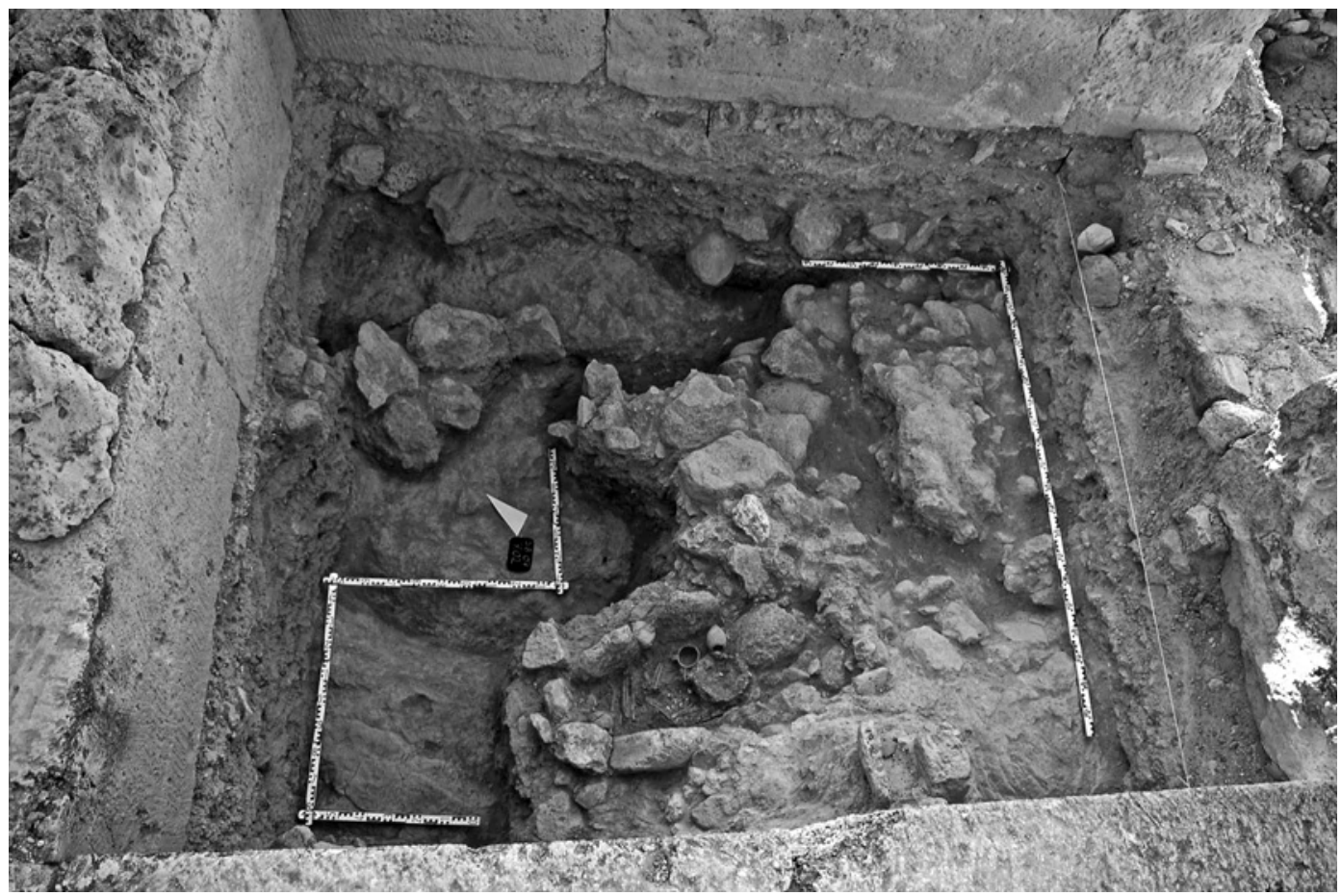

2 Südbau. Westraum mit Kindergrab und Steinpackung. Ansicht von Westen

Um eine mögliche westliche Ausdehnung des sepulkralen Befundes unter dem Ostraum zu bestimmen, wurde in der Kampagne 2007 auch das Areal unter dem Westraum in die Untersuchung einbezogen. War hier bereits zu Beginn der Grabung 2002 eine rinnenförmige Vertiefung (〉Opferrinne $)$ festgestellt worden, die in einen Bothros in der Nordostecke mündete, in dessen unteren Schichten sich vermehrt protogeometrische Keramik gefunden hatte ${ }^{2}$, so zeigte sich zum Abschluss der Kampagne 2006 in einer Testsondage unter dem vorerrichtungszeitlichen Boden $(+7.65 \mathrm{~m})$ in der Nordostecke ein dunkles, aschiges Stratum, welches ebenfalls protogeometrische Keramik enthielt. Darüber hinaus erschienen in dem betreffenden Stratum die Oberkanten zweier ovaler Steinsetzungen, deren Niveau $(+7.31 \mathrm{~m})$ mit den Bestattungen des Ostraumes übereinstimmte.

Im Zuge der Untersuchungen 2007 wurde in der westlichen Hälfte des Westraumes ein 1 m langes, Nordwest-Südost ausgerichtetes Steinkistengrab aufgedeckt, welches eine mit dem Schädel nach Südosten weisende Kinderbestattung und mehrere Beigaben enthielt (Abb. 2). Das keramische Inventar umfasst eine kleine attische Lekythos-Oinochoe mit stehenden, gegitterten Dreiecken auf der Schulterzone, eine attische schwarzgefirnisste, einhenkelige Tasse sowie eine handgemachte, tongrundige korinthische Spitzpyxis mit Deckel und Ösenhenkeln (Abb. 3) $)^{3}$. Die nichtkeramischen Beigaben bestehen aus einer $10 \mathrm{~cm}$ langen Eisennadel mit aufgeschobenem, gelängtem Kugelkopf aus Bronze und eiserner Endscheibe ${ }^{4}$, einem reifförmigen, bronzenen Lockenring sowie einem kleinen Halskollier aus 14 Fritteringen und einer mittig platzierten Perle aus schwarzem Steatit (Abb. 3). Form und Bemalung des kleinen Kännchens wie auch die oblonge Form des bronzenen Nadelkopfes erlauben, die Bestattung dem ersten Viertel des 9. Jahrhunderts v. Chr. zuzusprechen ${ }^{5}$. Die Grab-

${ }^{2}$ Felten u. a. (Anm. 1:2003) 48 mit Abb. 9

3 Vgl. C. A. Pfaff, Geometric graves in the Panayia field at Corinth, Hesperia 76, 2007, 501 f. Abb. 43; ferner K. Kokkou-Biride,

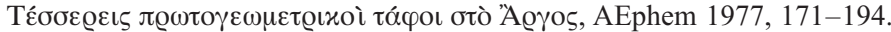

4 Typus B 3 nach I. Kilian-Dirlmeier, Nadeln der frühhelladischen bis archaischen Zeit von der Peloponnes, PBF XIII 8 (München 1984) 69 Taf. 9, 231; 10, 242. R. S. Young, An Early Geometric grave near the Athenian Agora, Hesperia 18, 1949,297 Nr. 26. 27 Taf. 72; P. Jacobsthal, Greek pins and their connections with Europe and Asia (Oxford 1956) 2 Abb. 5; H. Müller-Karpe, Die Metallbeigaben der früheisenzeitlichen Kerameikos-Gräber, JdI 77, 1962, 59-129; 109 Abb. 27 , Nr. 4.

${ }^{5}$ Zum Kännchen vgl. E. L. Smithson, The tomb of a rich Athenian lady, ca. 850 B.C., Hesperia 37, 1968,86 Taf. $21,4$. 


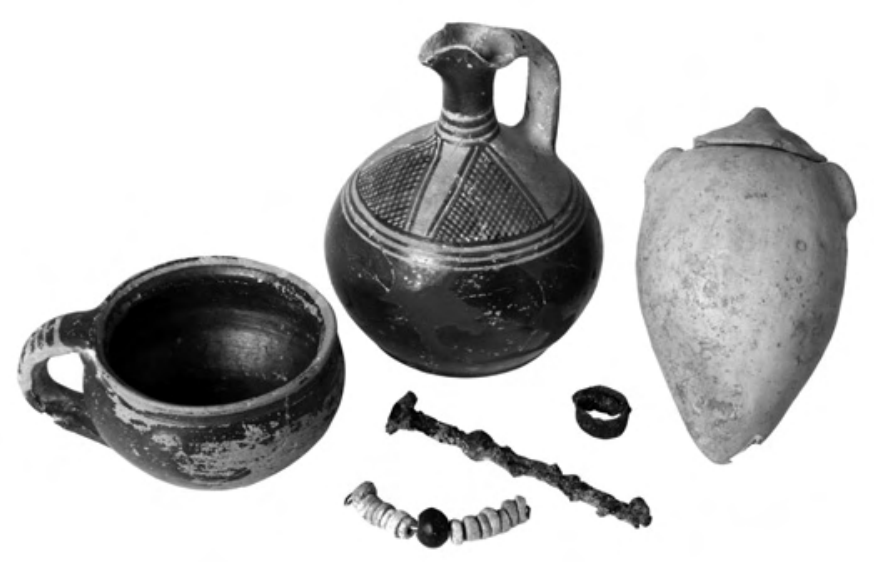

3 Westraum. Beigaben aus frühgeometrischem Kindergrab

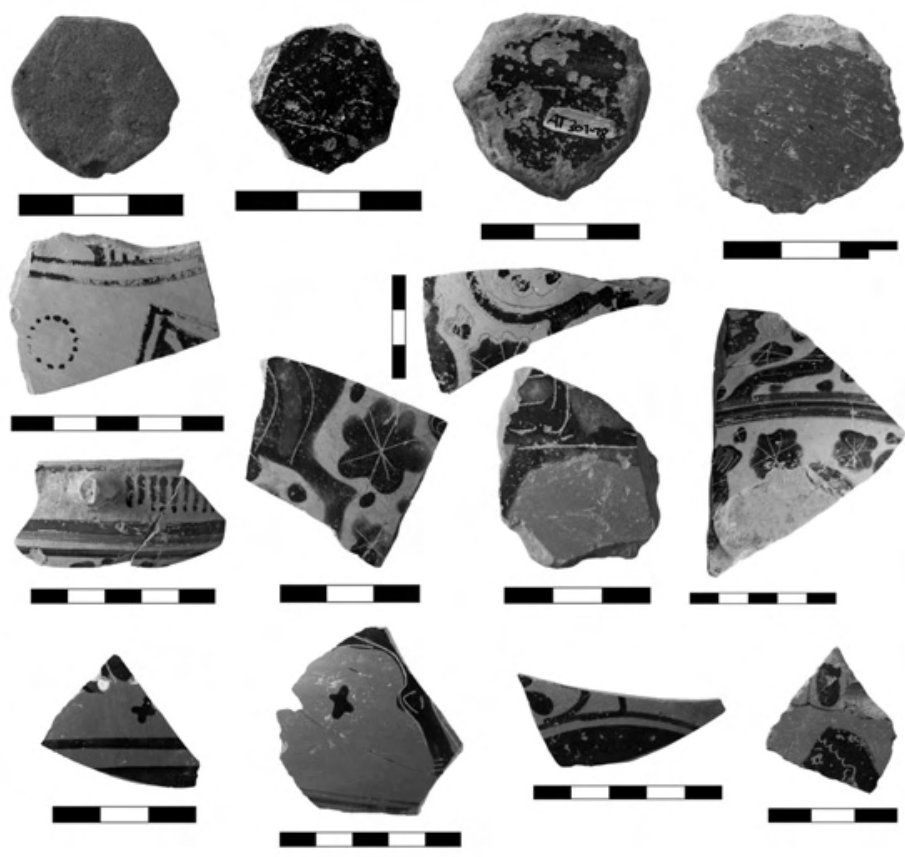

4 Westraum. Keramik und >pessoi< auf der Steinpackung. Auswahl

sohle bestand, wie bei früheisenzeitlichen Bestattungen üblich, aus einer Bettung aus Muschelschalen, Schnecken und kleineren Flusskieseln, der Zustand des Grabbefundes entsprach den sekundären Störungen an den Bestattungen im Ostraum. Eine Grababdeckung fehlte völlig, darüber hinaus war der Schädel des Skeletts stark zerdrückt. Das Grab war - wie die Bestattungen im Ostraum - in eine dichte Steinpackung eingetieft. Auf dieser fanden sich Fragmente früh- und hocharchaischer korinthischer, attischer und vermutlich ostgriechischer Gefäße sowie mehrere grob zugeschnittene Scheiben aus Keramikbruch (>pessoi<), wie sie bereits 2006 in der früharchaischen Bothrosfüllung unter Ostbau 0 enthalten waren (Abb. 4). Die Funde belegen, dass vor der Mitte des 6. Jahrhunderts v. Chr. in die Steinpackung großflächig eingegriffen worden war. Im Zuge dieser Maßnahmen dürfte es auch zu der sekundären Störung der Kinderbestattung gekommen sein.

Ein zweites, allerdings weitestgehend zerstörtes Steinkistengrab mit einer adulten Bestattung wurde in der Nordhälfte des Westraumes angetroffen. Das Skelett, welches nur noch aus Schädel, einer kleineren Rippenpartie und Resten der oberen Extremitäten bestand, befand sich in verlagerter Position, die Steinkiste war bis auf zwei Seitenplatten der nördlichen Langseite entfernt. Im Nordund Ostbereich des Westraumes sowie südlich des Kindergrabes führten diese festgestellten sekundären Eingriffe bis zum gewachsenen Fels hinab, lediglich nördlich des Kindergrabes konnte ein Teilstratum festgestellt werden, welches neben wenigen prähistorischen Scherben ausschließlich protogeometrische Keramik enthielt (Abb. 5). Im Störungshorizont westlich und südlich des Kindergrabes konnten dagegen neben wenigem prähistorischem und protogeometrischem Material vermehrt früh- und hocharchaische attische und korinthische Keramik, darunter zwei Miniaturskyphoi, sowie weitere spessoi< festgestellt werden (Abb. 6). Zu den nichtkeramischen Funden zählt eine komplett erhaltene mykenische Doppelaxt aus Bronze (Abb. 7) ${ }^{6}$.

\footnotetext{
${ }^{6}$ H. G. Buchholz, Zur Herkunft der kretischen Doppelaxt. Geschichte und auswärtige Beziehungen eines minoischen Kultsymbols (München 1959) Taf. 2. 4. 6; H. G. Buchholz, Die Doppelaxt, eine Leitform auswärtiger Beziehungen des ägäischen Kulturkreises?, PZ 38, 1960, 39-71; C. Mavriyannaki, La double hache dans le monde hellénique à l’âge du bronze, RA 1983, 195-228; A. T. Hodge, The labrys. Why was the double axe double?, AJA 89, 1985, 307 f.; R. D. G. Evely, Minoan Crafts. Tools and techniques, SIMA 92, 1 (Göteborg 1993) 41-55.
} 
Der keramische Befund in der Teilfläche nördlich des Kindergrabes verweist die Anlage der Steinpackung in protogeometrische Zeit. Ein kleiner, im Gegensatz zur dichten Verfüllung gelegt wirkender Mauerrest bildet möglicherweise den westlichen Fortsatz einer kurzen Mauerpartie, die 2006 im Ostraum festgestellt wurde und aufgrund des keramischen Befundes in die Phase FH II $\mathrm{zu}$ datieren ist. Entsprechend dem Befund im Ostraum wurden demnach auch im Bereich unter dem Westraum die früheisenzeitlichen Bestattungen in vorhandene prähistorische Baumasse eingetieft, welche bei der Anlage der Gräber weit-
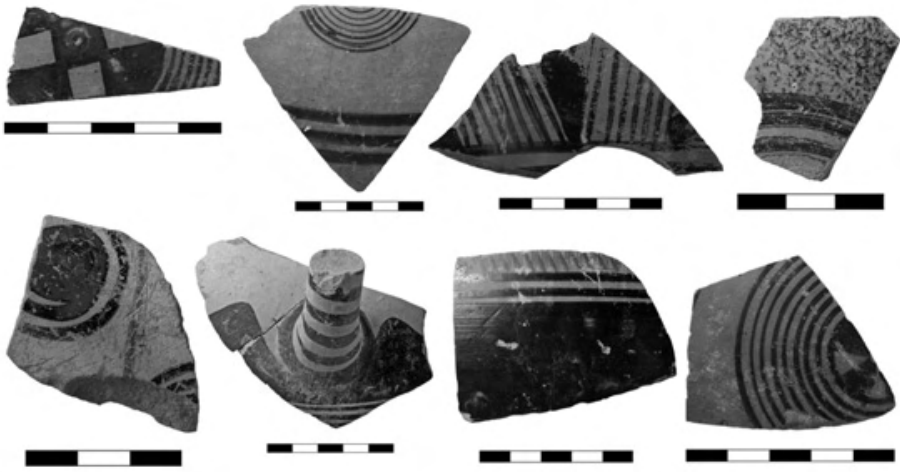

5 Westraum. Mykenische und protogeometrische Keramik nördlich des Kindergrabes. Auswahl gehend planiert worden war $^{7}$.

\section{Westannex II}

Um den möglichen weiteren Verlauf des früheisenzeitlichen Sepulkralensembles unter dem Südbau zu bestimmen, wurde das westseitig anschließende Raumkompartiment im Westannex II ebenfalls untersucht. Hier ließ sich unter einem Stratum, welches seit Beginn der Grabungen freigelegen hatte und welches einen gemischten keramischen Befund enthielt, ein fester grauer Lehmestrich $(+7.80 \mathrm{~m})$ feststellen, der an allen Seiten unter die Unterkanten der baulichen Strukturen des Südbaus verläuft. Das in der Bodenfütterung enthaltene, stark zerscherbte Keramikmaterial datiert mit seinen spätesten Exemplaren in das frühere 6. Jahrhundert v. Chr. (Abb. 8, 2). Bei dem grauen Estrichboden (+7.80 m) dürfte es sich damit um den westseitig leicht abfallenden Ausläufer des hocharchaischen Nutzungshorizontes (+7.92 m) handeln, welcher der Errichtung der spätarchaischen Anlage des Südbaus vorausgeht und der möglicherweise mit der Ost-West verlaufenden Stützenkonstruktion im Hof des Südbaus zu verbinden ist ${ }^{8}$.

Unter dem grauen Lehmestrich verlief in der Südhälfte des Westannexes II ein ca. $1 \mathrm{~cm}$ dicker, heller weißer Kalkmörtelboden (+7.73 m), welcher ab der Raummitte nach Norden allerdings komplett ausreißt (Abb. 8, 1). Dieser weiße Kalkestrich führte zwischen und unter den seitlichen Türköpfen der spätarchai-

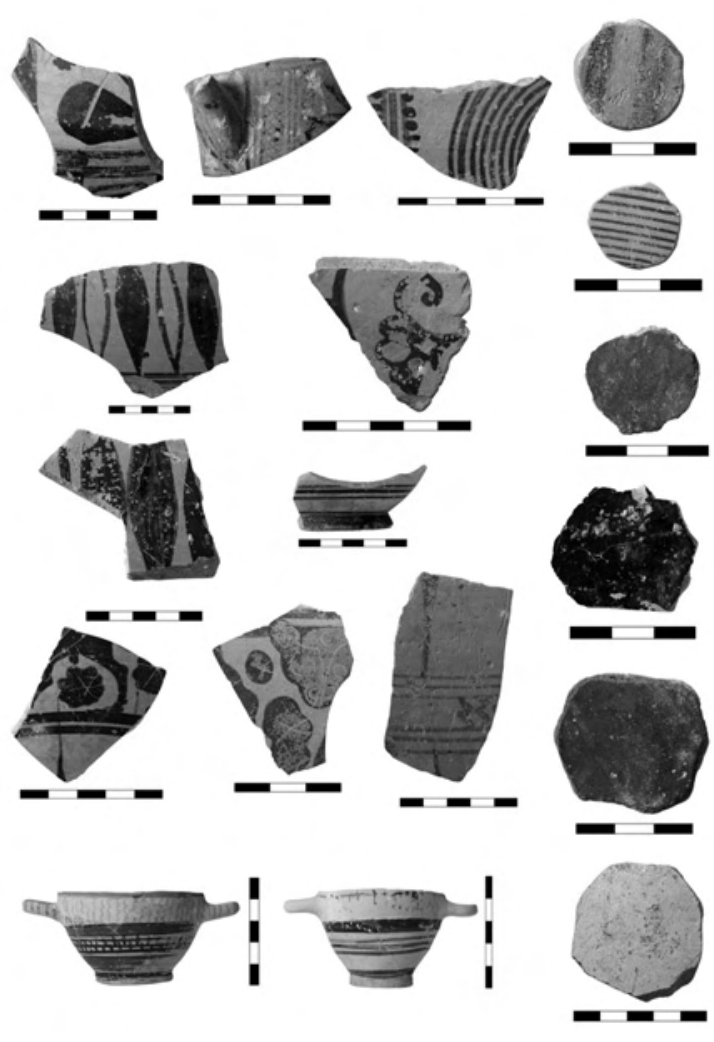

6 Westraum. Keramik und >pessoi` aus der Steinpackung. Auswahl

schen Anlage von Westannex II hindurch konstant bis zur südlichen Grabungsgrenze. In der ausgerissenen nördlichen Fläche erschien auf geringfügig tieferem Niveau (+7.65 m) eine weitere, lehmige braune, feste

\footnotetext{
${ }^{7}$ Diese Einebnungen betreffen auch die südliche Peripherie, da unter dem Hof des Südbaus planierte Baumasse frühmykenischer Zeitstellung angetroffen wurde. Darin befindliche Leerstellen stammen möglicherweise von abgeräumten früheisenzeitlichen Bestattungen; vgl. Felten u. a. (Anm. 1:2005) 11 Abb. 4.

${ }^{8}$ Felten u. a. (Anm. 1:2005) $10 \mathrm{f}$.
} 

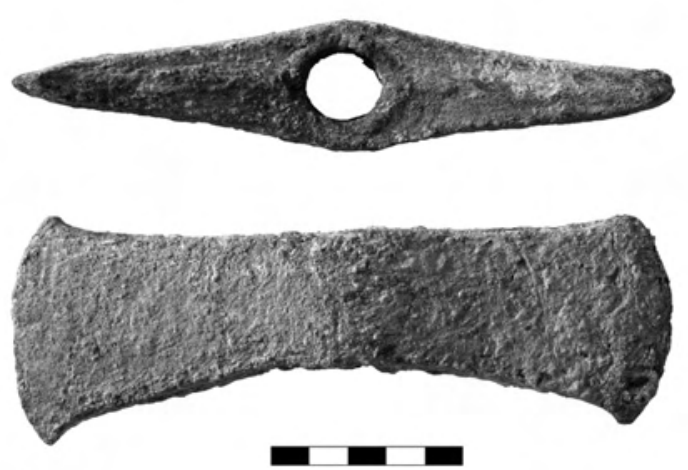

7 Westraum. Mykenische Doppelaxt aus Bronze

Lauffläche, welche mit dem über den Bestattungen befindlichen Laufhorizont und der >Opferrinne $<$ im Westraum (+7.65 m) übereinstimmen dürfte. Bereits auf diesem Niveau zeigte sich allerdings in der Nordostecke von Westannex II die Oberseite einer dichten und wie verbacken wirkenden Steinsetzung, welche die westliche Fortsetzung der die früheisenzeitlichen Bestattungen beinhaltenden Steinpackung im Westraum darstellt.

In der Folge der Untersuchung ließ sich diese dichte Steinsetzung in der Nordostecke bis auf den gewachsenen Fels verfolgen. Von Bedeutung ist allerdings, dass die gesamte übrige Fläche des nördlichen Raumkompartiments von Westannex II von einer homogenen, sehr lockeren, mit-
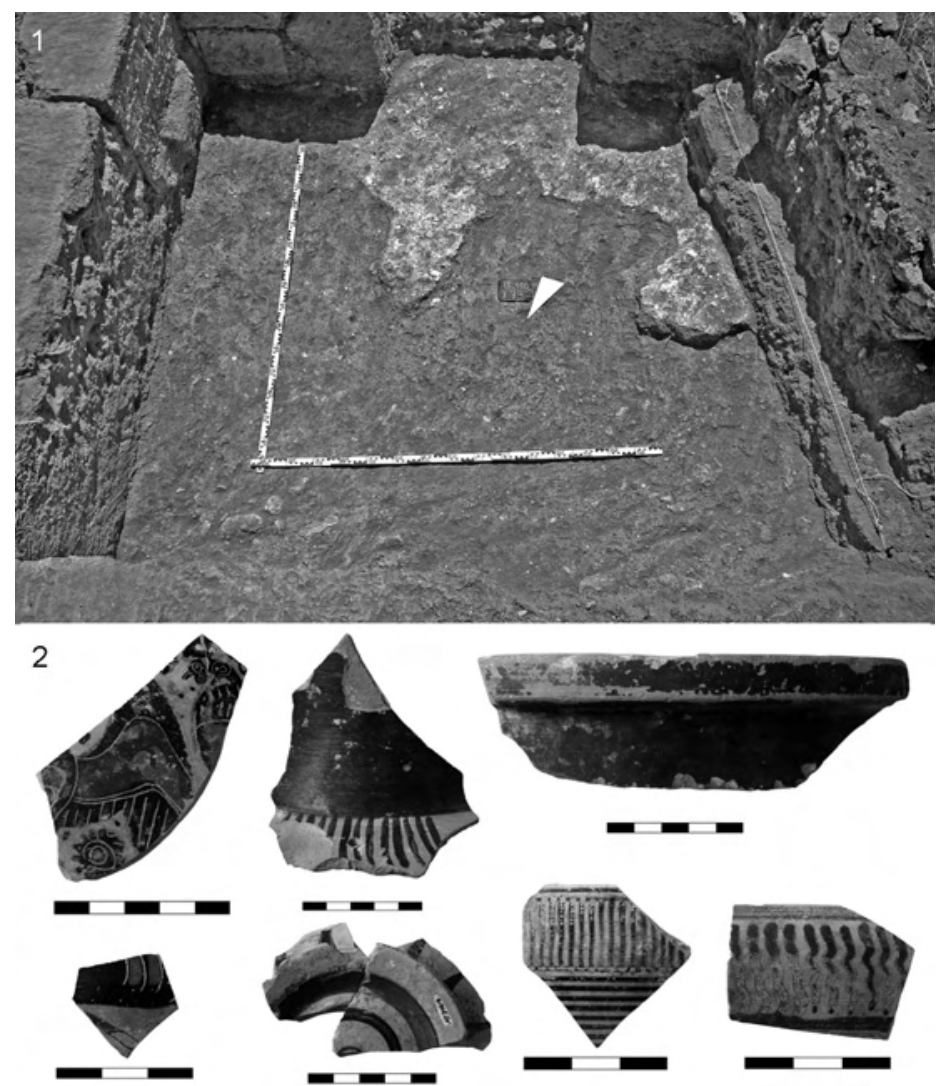

8 Westannex II. Weißer Kalkestrich $+7.65 \mathrm{~m}$ (1) und Keramik aus der oberen Lauffläche $+7.80 \mathrm{~m}$. Auswahl (2) tel- bis großsteinigen Verfüllung erfasst wurde, die bis auf den gewachsenen Fels $(+6.78 \mathrm{~m})$ reichte. Diese Verfüllung liegt auf bzw. stößt durch die Reste eines lehmigen Fußbodens (+6.93 m), unter dem sich vermehrt mykenische Keramik befand. Der Rest eines dreisteinigen Mauerzuges gehört möglicherweise zu der direkt auf dem Fels verlegten prähistorischen Bebauung.

\section{Befundinterpretation Südbau}

Nach den bisherigen Grabungsergebnissen können für das Areal unter dem Südbau die wesentlichen Nutzungsphasen und baulichen Maßnahmen in Grundzügen nachgezeichnet werden. Als gleichsam rituelles Herz des Westkomplexes kann der Südbau dabei auch in die Phasensequenz der übrigen Gebäudeeinheiten des gesamten baulichen Ensembles am Westende des Kaps eingebunden werden:

In die vorhandene prähistorische Bausubstanz am Westende von Kap Kolonna, die neben geringen Strukturen der Phase FH II vor allem die frühmykenische Epoche umfasst, wurden in protogeometrischer bis frühgeometrischer

Zeit eine massive Steinpackung angelegt und Bestattungen eingetieft. Gleichzeitig wurde an den nördlichen und - nach den Hinweisen im Ostraum - eventuell auch den südlichen Ausläufern dieses sepulkral genutzten Areals eine Reihe kreisförmiger Steinplattformen verlegt ${ }^{9}$.

Die Anlage des in der Nordostecke des Westraumes freigelegten Bothros, der in seinen untersten Straten vorwiegend protogeometrische Keramik enthielt und dessen Areal bis in die Spätzeit des Südbaus als Deponierungsplatz von Votivgaben benutzt worden ist, ist chronologisch nicht eindeutig zu bestimmen. Mög-

\footnotetext{
${ }^{9}$ Felten u.a. (Anm. 1:2004) 107 Abb. 11; Felten u. a. (Anm. 1:2006) 18 Abb. 13.
} 
licherweise wurde er im Zusammenhang mit den runden Steinplattformen bereits im 10. Jahrhundert v. Chr. angelegt. Die Eintiefung des Bothros ist vielleicht aber auch mit der Nord-Süd verlaufenden, rinnenartigen Einsenkung (〉Opferrinne ) zu sehen, die mit dem festen Lehmfußboden $(+7.65 \mathrm{~m})$ im Westraum und der unteren Lauffläche (+7.65 m) im nördlichen Raumkompartiment von Westannex II in Zusammenhang steht. Diese Maßnahmen, die wohl aus einer süd- und westseitigen Anplanierung und Abgleichung des Geländes mithilfe einer dichten Rollsteinpackung bestanden, lassen sich aufgrund des keramischen Materials einer Zeit vor der Mitte des 6. Jahrhunderts v. Chr. zuordnen. Im Zuge dieser Aktivitäten wurde, wie bereits angeführt, in den Bestand der früheisenzeitlichen Bestattungen z. T. massiv eingegriffen, die steinernen Grabmarkierungen (>grave-markers $\triangleleft$ ) wurden dagegen in ihren Positionen belassen und waren im während des 7 . und 6. Jahrhunderts v. Chr. genutzten Gelände noch sichtbar.

Eine weitere Gestaltung der ursprünglich rein sepulkral genutzten Zone erfolgte vor der Mitte des 6. Jahrhunderts v. Chr. Hierzu gehören der vorerrichtungszeitliche Boden (+7.92 $\mathrm{m}$ in West- und Ostraum sowie im Hof des Südbaus) und der westseitig leicht abgesenkte Laufhorizont in Westannex II (+7.80 m). Auch bei dieser Geländekonzeption müssen die Oberseiten der beiden Steinmale (>grave-marker $\iota$ ) noch sichtbar gewesen sein. Außer der Ost-West verlaufenden Stützenstellung im Hof des späteren Südbaus (Abb. 9, I), die möglicherweise mit diesen Maßnahmen zu verbinden ist und die vielleicht eine Eingangskonstruktion für das Areal gebildet hat, können für diese Phase allerdings keine baulichen Strukturen identifiziert werden ${ }^{10}$.

Mit der Errichtung des aus Porosquadern und großformatigen Orthostaten bestehenden Südbaus sowie von Ostbau 0 und der massiven Orthostatenstruktur im Norden am Ende des 6. bzw. am Anfang des 5. Jahrhunderts v. Chr. (Abb. 9, I) verschwinden die Spitzen der früheisenzeitlichen Steinmale (>grave-marker $)$ unter dem Boden (Fußboden $+8.08 \mathrm{~m}$ ) und der Nordwand des Südbaus. Einem der Steinmale wird dabei aber durch sorgfältiges Ausschneiden der Orthostatenunterseiten in der Nordwand umfassend Rechnung getragen.

Die folgende sepulkral-rituelle Nutzung des Südbaus (Abb. 9, II-III) und des Ostbaus I und II, bis hin zu dessen Ende im späteren 5. Jahrhundert v. Chr. und seiner abschließenden Verfüllung, wird neben den Befunden an Symposiumskeramik vor allem im Bereich über dem Bothros in der Nordostecke des Westraumes und durch seine Votivdepots veranschaulicht ${ }^{11}$. Dass auch das Areal von Westannex II in diese Aktivitäten einbezogen war, belegt ein bereits am Ende der ersten Grabungskampagne 2002 freigelegtes, kleines Depot an Miniaturgefäßen in dessen Südwestecke ${ }^{12}$.

Mit der Verfüllung des Südbaus im späteren 5. Jahrhundert v. Chr. liegen keine Anzeichen für rituelle Aktivitäten in dieser Zone des Westkomplexes mehr vor (Abb. 9, IV). Ungeklärt ist bislang, ob, wo und in welcher Gestalt rituelle Praktiken während der folgenden zwei Jahrhunderte bis zur baulichen Neukonzep-

\footnotetext{
${ }^{10}$ Felten u. a. (Anm. 1:2005) 11 Abb. 4.

11 Vgl. Felten u. a. (Anm. 1:2003) 48-51 Abb. 10-12.

12 Felten u. a. (Anm. 1:2003) 50 Abb. 15; eine ähnliche Nutzungsabfolge lässt sich auch für das >Heroon of the crossroads in Korinth nachweisen; vgl. C. K. Williams II - J. E. Fisher, Corinth 1972. The forum area, Hesperia 42, 1973 , 6-12.
} 
tion des Areals in hellenistischer Zeit weiterhin ausgeübt worden sind. Abgesehen von verstreuter Keramik, hier vor allem stempelverzierte Schwarzfirnissware, sowie dem Rest einer festgetretenen Lauffläche über der Ostterrasse konnten klar bestimmbare Nutzungshorizonte, geschweige denn bauliche Strukturen, dieser Zeit im gesamten Bereich des Westkomplexes noch nicht identifiziert werden. Der Befund belegt bislang nur, dass das Areal in den Bereichen Ostbau, Oststraße und Südbau bis zur Neubebauung des Geländes im Hellenismus als eine offene, von Verkehr frequentierte Zone genutzt wurde, was nicht zuletzt auch durch die Spurrillen auf der Ostmauer des Südbaus und die stark abgetretenen Oberkanten der polygonalen Westwand von Ostbau I bezeugt wird. Ferner weist die Nordmauer des Südbaus oberseitig starke Erosionseinwirkungen auf, die erst in Zusammenhang mit der hellenistischen Überbauung durch den Kernbau abgeglichen und verschlossen worden sind. Ihre Reste müssen demzufolge nach der Verfüllung des Südbaus partiell sichtbar und der Witterung ausgesetzt gewesen sein. Nicht zuletzt sei auf die ebenfalls beträchtlichen erosionsbedingten Abwitterungen an der Südseite der aus großen Orthostaten bestehenden, L-förmigen Struktur nördlich des Kernbaus hingewiesen, welche im Zuge des hellenistischen Neubaus mit einer Lage aus Mörtel und Keramikfragmenten zur Aufnahme des farbigen Wandputzes ausgefüllt und abgeglichen wurden ${ }^{13}$.

Für die Zeit nach der Verfüllung des Südbaus im späteren 5. Jahrhundert v. Chr. dürfte für das betreffende Gelände somit eine offene Freifläche zu veranschlagen sein, in welcher die Reste der früheren Bebauung in manchen Zonen nur noch als ruinöse und abgewitterte Mauerzüge sichtbar gewesen sind (Abb. 9, IV).

Es stellt sich die Frage, ob der auffallende Hiatus in Bezug auf Fundaufkommen und Baubestand der folgenden zwei Jahrhunderte im Bereich des Westkomplexes in Zusammenhang mit den historischen Ereignissen seit der Mitte des 5. Jahrhunderts auf Ägina verbunden werden kann ${ }^{14}$. Die 50-jährige Zeitspanne zwischen der Einnahme Äginas durch Athen 457/456 v. Chr. und der Rückkehr der restlichen Bevölkerung 404 v. Chr. hat möglicherweise auch in der Nutzungsabfolge im Westkomplex ihren Niederschlag gefunden:

Die Funde in den untersten Straten der Lehmziegelverfüllung des Südbaus weisen darauf hin, dass mit der Unterwerfung der Polis unter das athenische Diktat die baulichen und rituellen Aktivitäten im Westkomplex zunächst noch nicht geendet haben ${ }^{15}$. In diese Zeitspanne dürften die Errichtung von Ostbau II, Veränderungen im Südbau sowie die Öffnung der großen, L-förmigen Orthostatenformation im Norden gehört haben (Abb. 9, III). Die wesentlichen demographischen Strukturen der äginetischen Gentile und ihrer ausgeübten Praxis des Phratrienkultes sind demnach vermutlich weiter erhalten geblieben ${ }^{16}$. Die radikale Beendigung der rituellen Aktivitäten, die Verfüllung des Südbaus, datiert nach dem keramischen Befund in das fortgeschrittene 5. Jahrhundert v. Chr. und könnte sich zeitlich mit der gewaltsamen Exilierung der Bevölkerung im Jahre 431 v. Chr. durchaus decken.

\footnotetext{
${ }^{13}$ Vgl. Felten u. a. (Anm. 1:2006) 17 Abb. 11. Zur Hinterfütterung der farbigen Stuckwände in Eretria s. K. Reber, Die klassischen und hellenistischen Wohnhäuser im Westquartier, Eretria 10 (Lausanne 1998) 116 Abb. 182. Die inkrustierten Quaderwände erwähnt G. Welter, Aeginetica XXV-XXVI, AA 1954, 46; im Zuge der neueren Grabungen im Westkomplex wurden mehrfach kleinste Fragmente von rotem und gelbem Wandputz festgestellt.

${ }^{14}$ Die radikale Beendigung der rituellen Aktivitäten in dieser Zone, die Verfüllung des Südbaus, für den sich bislang an keiner Stelle eine konstante Tradierung feststellen ließ, dürfte mit einer ebenso kompletten demographischen Zäsur in Verbindung zu bringen sein, der Vertreibung der äginetischen Bevölkerung im Jahre 431 v. Chr., teils auf die Peloponnes, teils in eine gewissermaßen `ägäische Diaspora (Thuk. 2, 27). Warum diese radikale Exilierung erst 25 Jahre nach der Einnahme Äginas erfolgte, ist nicht ganz geklärt; möglicherweise haben sich trotz Unterwerfung in der äginetischen Bevölkerung noch die wesentlichen eigenen sozialen Gentilstrukturen und damit potenzielle Grundlagen einer bedrohlichen Opposition erhalten, was - gewissermaßen im Vorhof Athens - von den Besatzern allmählich als ein gefährlicher und letztendlich untragbarer Zustand angesehen wurde. Die mit Unterstützung Spartas in Thyrea in der südargolischen Landschaft Kynouria angesiedelten Ägineten werden 424 v. Chr. von einer athenischen Heeresmacht angegriffen (Thuk. 2, 55-57). Die für die Exil-Ägineten opferreichen Kampfhandlungen, die Deportation der Überlebenden nach Athen und schließlich die von der Versammlung verordnete und wohl auch durchgeführte Ermordung der Deportierten tragen den Charakter eines Genozids und dürften zugleich die Auslöschung der letzten noch bestehenden alten Gentilstrukturen in der äginetischen Exilbevölkerung bedeutet haben. Auch wenn nach der literarischen Überlieferung dem in der >Diaspora verstreut lebendem Rest der alten Bevölkerung durch den spartanischen Feldherrn Lysander 404 v. Chr. die Möglichkeit gegeben wurde, auf seine Heimatinsel zurückzukehren (Xen. 2, 2, 9; Plut. 14), so ist es doch unwahrscheinlich, dass aufgrund des durchgreifenden demographischen Aderlasses von Thyrea und Athen die alten geordneten Gentilstrukturen der Rückkehrer erhalten geblieben sind.

${ }^{15}$ Felten u. a. (Anm. 1:2006) 12 f. Abb. 6.

${ }^{16}$ Diese demographische >Infrastruktur` war für die erzwungene Mitgliedschaft im Attisch-Delischen Seebund wohl zunächst auch weiterhin notwendig.
} 
Die in der Folge auf der Insel angesiedelten athenischen Kleruchen hatten selbstverständlich keine Veranlassung, einen hier ursprünglich ansässigen, ihnen fremden - weil äginetischen - Gentil- und Phratrienkult weiterhin auszuüben. Während eine kontinuierliche Kultpraxis im östlich gelegenen Hauptheiligtum einer gleichsam panhellenisch übergeordneten Hauptgottheit Apollon für die athenischen Neusiedler wohl keine Hemmschwelle gebildet hat, lassen sich hier baulich-restaurative Maßnahmen an den vorhandenen Sakralbauten trotzdem erst für die erste Hälfte des 4. Jahrhunderts v. Chr. nachweisen ${ }^{17}$. Der Westkomplex mit seinen Anlagen für den demographisch untermauerten Gentilkult der alten Polis bildete dagegen eine sozial-interne und spezifisch äginetische Institution, die es seitens der Besatzer letztlich abzuschaffen galt ${ }^{18}$. Es ist ferner zu vermuten, dass im sozialen Gefüge der 404 v. Chr. auf die Insel zurückgekehrten Restbevölkerung keine strukturellen Grundlagen für die Ausübung eines traditions- und familiengebundenen Gentil- und Ahnenkultes mehr vorhanden waren. Die dafür notwendigen alten Sozialstrukturen waren durch Exilierung, Deportation und Mord zerschlagen und ausgelöscht worden.

\section{b. Norderweiterung}

Umfassende bauliche Maßnahmen lassen sich im Westkomplex erst wieder mit der hellenistischen Neukonzeption des Areals feststellen (Abb. 9, V). In diesem Zusammenhang konzentrierte sich das Hauptgewicht der Arbeiten 2007 auf den Bereich des Nordbaus, dessen südliche Ausdehnung bereits 2006 mit dem Verlauf der gepflasterten Nordstraße festgestellt worden war (Abb. 10). Hierbei wurden in den oberen Geländeschichten flächendeckende und tief eingreifende Störungen angetroffen, die von den älteren Grabungen durch A. Furtwängler und G. Welter stammen dürften. Im Zuge dieser Arbeiten war darüber hinaus die hier anstehende byzantinische Bebauung weitgehend entfernt worden. Abgesehen von einigen wenigen verbliebenen Mauerresten hat sich nur eine $5 \mathrm{~m}$ lange und $4.5 \mathrm{~m}$ breite, tonnenüberwölbte Zisterne erhalten, welche den antiken Baubestand zwischen Kernbau und Nordbau zerstört hat (Abb. 11). Mehrfach befanden sich in den byzantinischen Bauresten vermauerte Spolien, darunter eine $93 \mathrm{~cm}$ hohe Trapezophore mit Delphin- und Doppelthyrsos-Darstellung (Abb. 13, 2) ${ }^{19}$.

\section{Nordbau}

Im Zuge der weiteren Arbeiten zeigte sich, dass die 2006 partiell angegrabenen, im Norden und Osten des östlich an den Kernbau anschließenden Hofes befindlichen Strukturen zu hellenistischen Gebäudeeinheiten gehören, die größere Ausmaße besaßen, als bisher angenommen. Durch die erhöhte Geländesituation im Nordbereich des Westkomplexes bedingt, liegen hier allerdings die byzantinischen und hellenistischen

\footnotetext{
${ }^{17}$ K. Hoffelner, Die Dachterrakotten des Artemistempels vom Apollon-Heiligtum in Ägina, in: N. A. Winter (Hrsg.), Proceedings of the International conference on Greek architectural terracottas of the Classical and Hellenistic periods, December 12-15, 1991, Hesperia Suppl. 27 (Princeton, NJ 1994) 99-112; K. Hoffelner, Das Apollon-Heiligtum. Tempel, Altäre, Temenosmauer, Thearion, Alt-Ägina 1, 3 (Mainz am Rhein 1999) 99 f. 114 f.; von einer baulich-kultischen Tätigkeit zeugt u. a. eine im Westkomplex verbaute kykladische Giebelwange eines Altars, dessen ursprünglicher Standort allerdings unbekannt bleibt, vgl. Felten u. a. (Anm. 1:2007) 105 f.; 107 Abb. 30.

${ }^{18}$ Dazu trugen nicht zuletzt wohl auch die mehrfachen Autonomieforderungen für Ägina seitens Sparta bei; nach der Überlieferung bei Thuk. 8, 91-92 wurde die von attischen Kleruchen besiedelte Polis Ägina im Jahr 411 v. Chr. das Opfer eines von dem Spartaner Agesandridas geleiteten Feldzuges. Wie durchgreifend diese wie auch die späteren Eroberungen durch Kassander und Demetrios Poliorketes gewesen sind, lässt sich aus dem vorhandenen Baubestand nicht eruieren.

19 Verdoppelung der Zapfen in der römischen Bacchus-Ikonographie bei einem spätseverischen Sarkophag in New York: A. M. McCann, Roman sarcophagi in The Metropolitan Museum of Art (New York 1978) 94 Nr. 109. Zum Typus der Trapezophore s. H. v. Hesberg, Tischgräber in Italien, AA 1980, 425 Abb. 9; R. H. Cohon, Greek and Roman stone table supports with decorative reliefs (Ann Arbor 1985) 21 Taf. D; C. F. Moss, Roman marble tables (Ann Arbor 1990) 44-52 (Typus 10); vgl. einen von Weinranken eingefassten Thyrsos auf einem spätklassischen oder hellenistischen Tischbein aus Kavalla: Cohon a. O. 170 (Kat. 2). Aus Akanthusblättern wachsende und mit Bändern umwickelte Thyrsoi sind ebenso an der Front von Trapezophoren aus Tivoli (vermutlich augusteisch) dargestellt: Cohon a. O. 208 f. (Kat. 45). In spätseverische Zeit gehört eine aus einem älteren Stück umgearbeitete Tischplatte mit der Weihinschrift an Caracalla als `Neos Dionysos〈, die in der frühchristlichen Bischofskirche von Ägina verbaut war; vgl. K. Hoffelner, Die Sphinx-Säule, Alt-Ägina 2, 4 (Mainz am Rhein 1996) 40-43; F. Felten, Kulte in Aigina-Kolonna, in: S. Buzzi - D. Käch - E. Kistler u. a. (Hrsg.), Zona Archeologica. Festschrift Hans Peter Isler (Bonn 2001) 129 mit der Annahme einer Provenienz der Tischplatte aus Kolonna.
} 


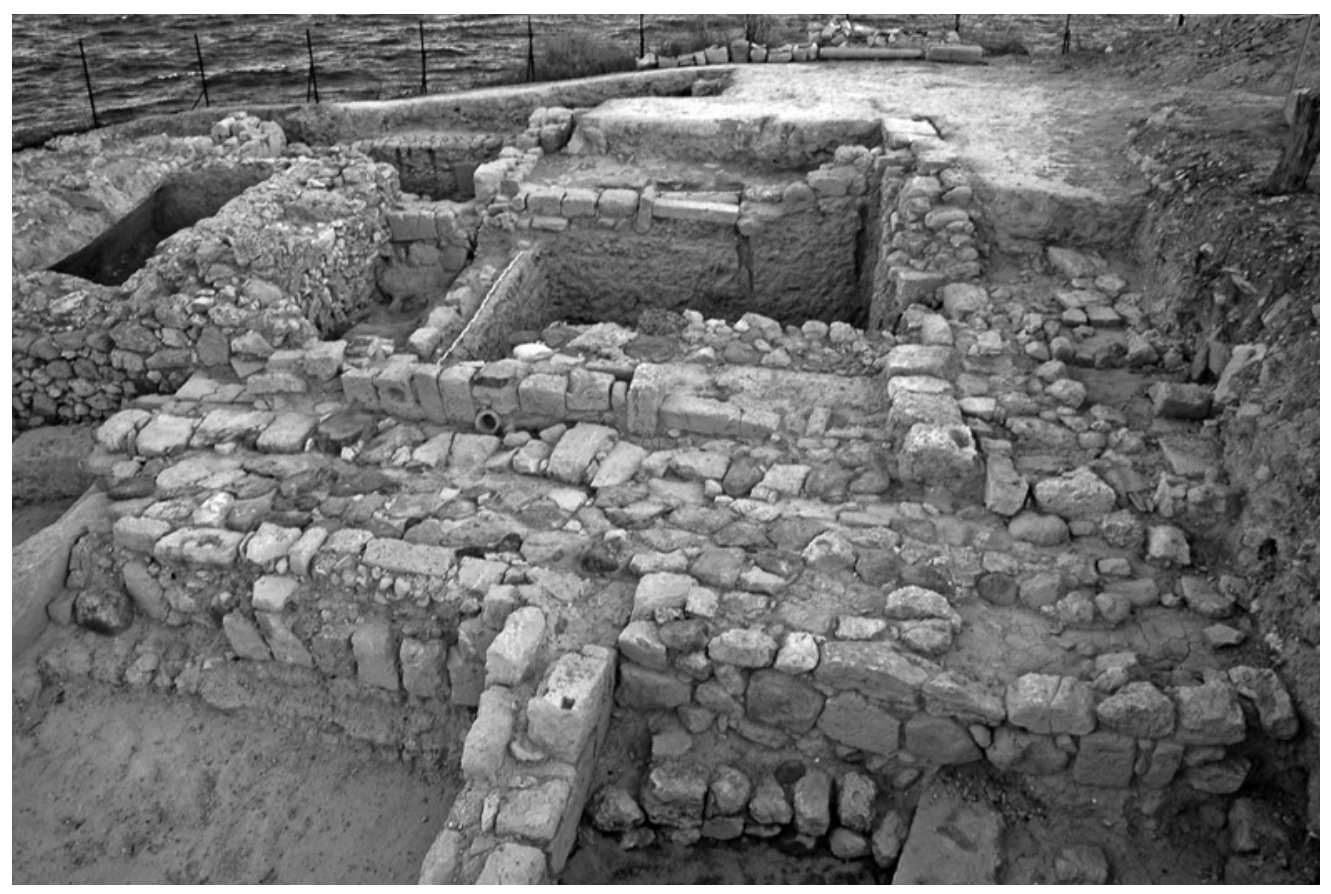

10 Westkomplex. Bereich Nordstraße, Nordostbau und Nordbau. Gesamtansicht von Süden

Nutzungshorizonte in einer derart dicht aufeinander wechselnden Abfolge, dass es zu partiell durchgreifenden Störungen im antiken Bauverband gekommen ist. Dementsprechend ergab sich auch in den obersten Erdschichten der von der Grabung erfassten Fläche ein gemischtes Stratum mit keramischem Fundmaterial frühbyzantinischer bis hoch- und späthellenistischer Zeitstellung (Abb. 12). Das Spektrum des hellenistischen Materials entspricht qualitativ dem Fundaufkommen der Kampagne von 2006 direkt auf der gepflasterten Nordstraße und besteht aus Reliefbechern und Lampen, Schüsseln mit kopfgestaltigen Appliken sowie größeren Gefäßen mit figürlichem Reliefdekor. Ferner lassen sich Fragmente von Westabhang-Ware, unverzierte Schwarzfirnisskeramik, Unguentarien, Gebrauchskeramik nebst gestempelten Amphoren und mehrere Webgewichte anführen.

Von besonderer Bedeutung - nicht zuletzt in Hinblick auf eine entsprechende, auf Kolonna baulich bislang nicht vertretene Epoche ${ }^{20}$ - ist ein Figuralkapitell, welches aus den angeführten obersten Schuttschichten stammt (Abb. 13,1). Das 19,5 cm hohe und 47,3 cm breite Kapitell ist aus weißem bis leicht bläulichem und relativ grob kristallinem Marmor gearbeitet und besitzt eine Dekoration aus flach reliefierten Rankenspiralen sowie drei vorspringenden Protomen in Gestalt gehörnter Löwengreifen. Ungewöhnlich ist die ovale, $29,3 \mathrm{~cm}$ lange Lagerfläche ${ }^{21}$. Das Figuralkapitell zeigt formale Verwandtschaft zu den sechseckigen Freikapitellen sowie den Pilasterkapitellen der sog. Kleinen Propyläen von Eleusis, die 49 v. Chr. begonnen wur$\operatorname{den}^{22}$. Diese wiederum können als eine Weiterentwicklung des Typus der sog. Chimärenkapitelle verstanden

${ }^{20}$ Vgl. H. R. Goette, Kaiserzeitliches auf Aigina, in: G. Brands - J. N. Andrikopoulou - D. Dexheimer - G. Bauchhenß (Hrsg.), Rom und die Provinzen. Gedenkschrift Hanns Gabelmann (Mainz am Rhein 2001) 87-94.

${ }^{21}$ Vgl. die Ovalsäulen mit Chimärenkapitellen der Bühnenwand des Dionysos-Theaters in Athen; E. v. Mercklin, Antike Figuralkapitelle (Berlin 1962) 593 f. (mit älterer Lit.).

${ }^{22}$ H. Hörmann, Die Inneren Propyläen von Eleusis, DAA 1 (Berlin 1932) 57-64; v. Mercklin (Anm. 21) 250 f. (mit älterer Lit.); G. Sauron, Les propyleés d'Appius Claudius Pulcher à Eleusis. L'art néoattique dans les contradictions idéologiques de la noblesse romaine à la fin de la république, in: J.-Y. Marc - J.-C. Moretti (Hrsg.), Constructions publiques et programmes édilitaires en Grèce entre le IIe siècle av. J.C. et le Ier siècle ap. J.C. Actes du colloque organisé par l'Ecole française d'Athènes et le CNRS 1995, BCH Suppl. 39 (Athen 2001) 270-276; vgl. Th. Kraus, Die Ranken der Ara Pacis. Ein Beitrag zur Entwicklungsgeschichte der augusteischen Ornamentik (Berlin 1953) 38; C. Börker, Blattkelchkapitelle (Berlin 1965) 21; W. D. Heilmeyer, Korinthische Normalkapitelle. Studien zur Geschichte der römischen Architekturdekoration, RM Ergh. 16 (Heidelberg 1970) 54; D. Grassinger, Römische Marmorkratere (Mainz am Rhein 1991) 34 f. 
werden $^{23}$, wobei die Motive der eleusinischen Kapitelle und in Abhängigkeit von diesen auch jene des äginetischen Kapitells auf dekorierten Ausstattungsgegenständen wie Tischfüßen, Kandelabern sowie Marmorkrateren begegnen und damit in den Kreis der vor allem für den römischen Kunstmarkt arbeitenden neuattischen Werkstätten verweisen ${ }^{24}$. In diesen $\mathrm{Zu}$ sammenhang gehört wohl auch das Detail des einzelnen Akanthusblattes an der Rückseite des Kapitells $^{25}$. Die auffallend rechteckige Form des Akanthus kommt bereits bei den Kapitellen des Odeions des Agrippa auf der Athener Agora vor und ist noch weiter fortgeschritten bei drei Kapitellen auf dem römischen Markt von Athen, die etwa in die Zeitenwende datiert werden können ${ }^{26}$.

Mit der Aufdeckung der antiken Baumasse wurde deutlich, dass das gesamte Areal nördlich der Nordstraße von einem zusammenhängenden, mehrräumigen Bau eingenommen worden ist, in dessen Struktur der bereits 2003 freigelegte >Schwellenbau (im Folgenden: Nordbau, Raum I) als westseitig abschließender Bestandteil integriert werden muss ${ }^{27}$. Den hinteren, d. h. nordseitigen Kern der Anlage bildet ein bislang aus drei Raumkompartimenten bestehendes, rechteckiges, $15 \mathrm{~m}$ langes und $5 \mathrm{~m}$ breites Gebäude, dessen Räume darunter, wie angeführt, auch der einstmalige >Schwellenbau< - identische Innenmaße von $4.10 \mathrm{~m}$ Breite bzw. $4.25 \mathrm{~m}$ Länge besitzen. Bei diesem Langbau dürfte es sich aufgrund

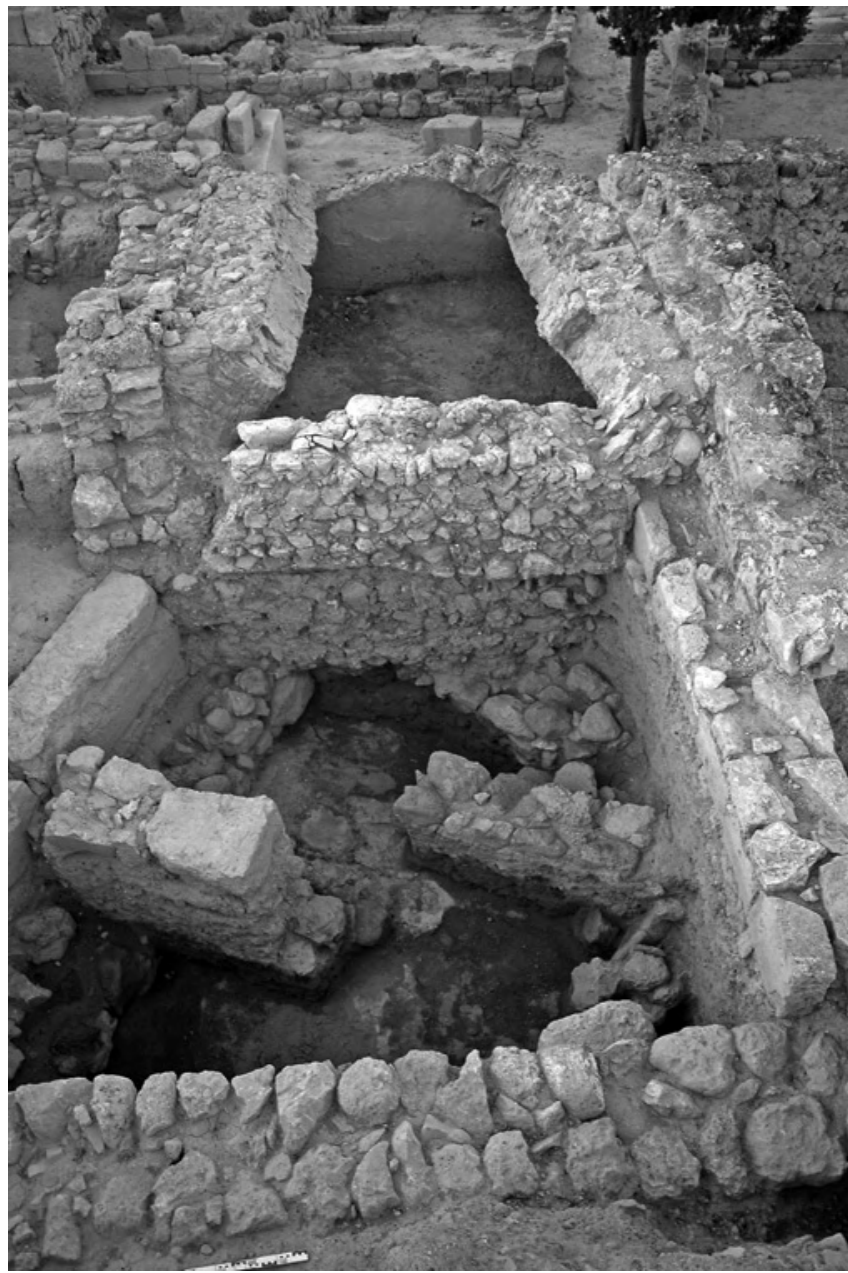

11 Nordbau, Raum II und byzantinische Zisterne. Ansicht von Norden der maßbezogen >standardisierten`Innenräume um ein Bankettgebäude gehandelt haben. Hingewiesen sei in diesem Zusammenhang auf den durch die parataktische Anordnung maßidentischer Raumeinheiten charakterisierten Bautypus, wie er etwa in den sog. Westoikoi im Demeterheiligtum von Pergamon auftritt ${ }^{28}$.

\footnotetext{
${ }^{23}$ Sauron (Anm. 22) 270; zu den Chimärenkapitellen s. H. Heinrich, Die Chimärenkapitelle, in: G. Hellenkemper Salies - H.-H. von Prittwitz und Gaffron - G. Bauchhenß (Hrsg.), Das Wrack. Der antike Schiffsfund von Mahdia (Köln 1994) 209-237.

${ }^{24}$ s. allgemein H.-U. Cain - O. Dräger, Die sogenannten neuattischen Werkstätten, in: Hellenkemper Salies - von Prittwitz und Gaffron - Bauchhenß (Anm. 23) 809-829 (mit älterer Lit.); zu den neuattischen Motiven auf den eleusinischen Kapitellen s. Sauron (Anm. 22) $270 \mathrm{f}$.

${ }^{25}$ Das Akanthushochblatt tritt in Griechenland erst unter dem Einfluss italisch-römischer Dekoration auf; s. F. Rumscheid, Untersuchungen zur kleinasiatischen Bauornamentik des Hellenismus (Mainz 1994) $263 \mathrm{f}$.

${ }^{26}$ Kapitelle des Odeions des Agrippa: Börker (Anm. 22) 25-28 (KK 30); Kapitelle aus dem römischen Markt: Börker (Anm. 22) 30 f. (KK 36a-c); die Verhärtung und Erstarrung der Blattform und die lineare, kantig strukturierte Blattoberfläche des Akanthus verweisen das Kapitell von Kolonna in spätaugusteisch-tiberische Zeit; zur Entwicklung des Akanthusblatts: Börker (Anm. 22) 28-43.

${ }^{27}$ Felten u. a. (Anm. 1:2003) 100-104.

${ }^{28}$ C. H. Bohtz, Das Demeterheiligtum, AvP 13 (Berlin 1981) 32-34 Taf. 43; ferner C. Börker, Festbankett und griechische Architektur, Xenia 4 (Konstanz 1983) 8-48; B. Bergquist, Sympotic space. A functional aspect of Greek dining-rooms, in: O. Murray (Hrsg.), Sympotica. A symposium on the symposion (Oxford 1990) 37-65; N. Bookidis, Ritual dining in the sanctuary of Demeter and Kore at Corinth, in: Murray a. O. 86-94; M. S. Goldstein, The setting of the ritual meal in Greek sanctuaries, 600-300 B.C. (Ann Arbor 1978) 143-154 (Aphaia-Heiligtum); V. Hinz, Der Kult von Demeter und Kore auf Sizilien und in der Magna Graecia, Palilia 4 (Wiesbaden 1998) 51-53. 114 Abb. 20; 116 Abb. 22 mit nichtstandardisierten Raumeinheiten (Eloro).
} 


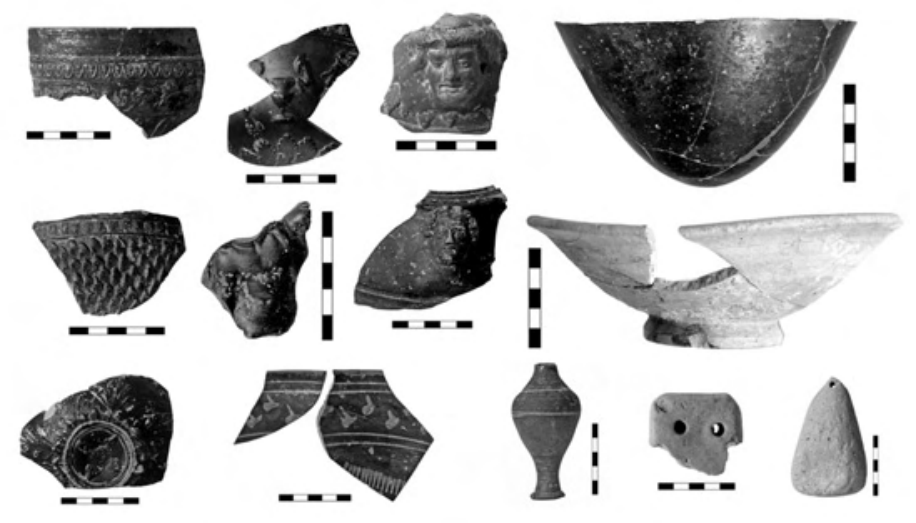

12 Nordbau. Keramik und Kleinfunde aus oberstem Mischstratum. Auswahl
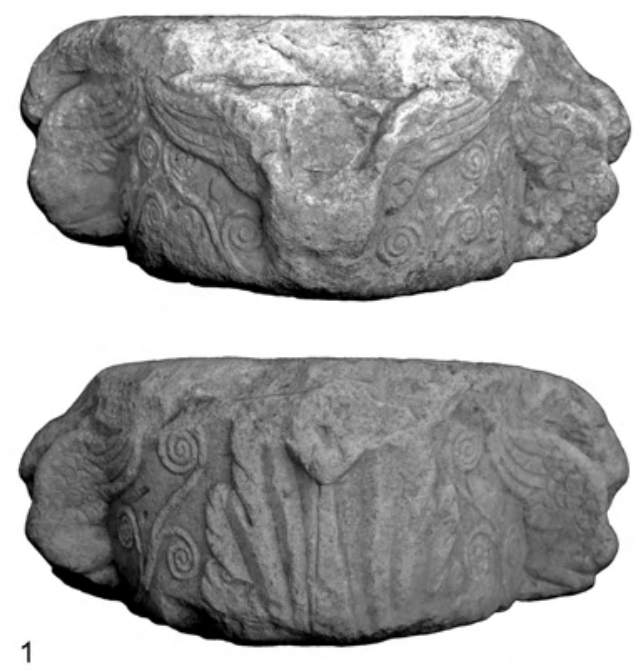

2

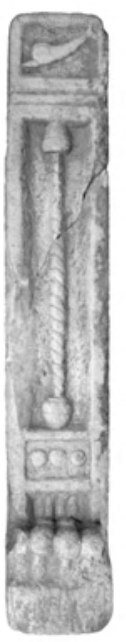

13 Nordbau. Figuralkapitell (1) und Trapezophore (2) aus oberstem Mischstratum

Die durchgreifenden Eingriffe seitens der z. T. unmittelbar aufsitzenden byzantinischen Baumasse haben den ursprünglichen Bodenhorizont der hellenistischen Bebauung umfassend in Mitleidenschaft gezogen. Aus einem byzantinischen Mauerrest stammen mehrere, bis zu $0.40 \mathrm{~m}$ große Brocken eines massiven Terrazzo-Fußbodens (Abb. 14). Seine unterste Bettung bildet eine Lage aus $8-10 \mathrm{~cm}$ langen, ovalen Kieseln in Schräg- bzw. Vertikalstellung, auf denen eine $4 \mathrm{~cm}$ dicke, weißliche Kalkmörtelschicht verstrichen war, die als Zuschlag Kies und viele Kleinstkiesel mit einer Länge von bis zu $4 \mathrm{~mm}$ enthielt. Das oberste Paviment besteht aus einer $1 \mathrm{~cm}$ dicken weißen und sehr feinen Kalkmörtelschicht, in der sich als Zuschlag in sschwimmender Verlegung viele, ca. $2 \mathrm{~cm}$ lange Flachkiesel weißgrauer bis bläulich schwarzer Färbung eingebettet befinden. Die Pavimentoberfläche ist kräftig abgeschliffen. Mit der Abfolge von statumen, rudus und nucleus repräsentieren die Reste dieses betonharten, sorgfältig geschliffenen Terrazzobodens eine Pavimentform, die bereits in der Ausstattung der spätklassischen Hausarchitektur zum Einsatz kommt und die hier insbesondere zur Bodengestaltung von Andrones gehört ${ }^{29}$. Im Baubefund des Nordbaus haben sich bislang jedoch keine Hinweise auf die ursprüngliche Lage und Höhe dieses Terrazzobodens ergeben. Von Bedeutung ist aber, dass in der Unterfütterung des ausgerissenen Bodens im 2003 freigelegten >Schwellenbau< viele kleine Eintiefungen festgestellt wurden, welche die Abdrücke des statumen bilden könnten ${ }^{30}$.

Südseitig an den Nordbau angesetzt befindet sich eine weitere Raumgruppe mit trapezoidem Grundriss (im Folgenden: Annex), deren Mauern mit einer Breite von $45 \mathrm{~cm}$ durchweg schmäler sind als die Wände des Nordbaus und die eine andere Verlegetechnik aufweisen. Dazu gehören die Verwendung unterschiedlicher Steinformate, stark springende Horizontalfugen sowie klaffende Vertikalfugen. Der westliche Anschluss an den Nordbau ist durch die byzantinische Tonnenzisterne allerdings gänzlich zerstört worden.

\footnotetext{
${ }^{29}$ Vitr. 7, 1; R. E. M. Moore, A newly stratum in Roman floor mosaics, AJA 72, 1968, 57-68; D. Salzmann, Untersuchungen zu den antiken Kieselmosaiken von den Anfängen bis zum Beginn der Terreratechnik (Berlin 1982) 42 f.; W. Müller-Wiener, Griechisches Bauwesen in der Antike (München 1988) 108-111; P. Ducrey - I. R. Metzger - K. Reber, Le Quartier de la Maison aux mosaïques, Eretria 8 (Lausanne 1993) 36-38; K. Reber, Die klassischen und hellenistischen Wohnhäuser im Westquartier, Eretria 10 (Lausanne 1998) 113-115; G. Lavas - G. Karadedos, Mauerwerk, Bodenbeläge und Anstrichtechnik eines spätklassischen Hauses in Maroneia, Thrazien, DiskAB 5 (Mainz am Rhein 1991) 140-147 Abb. 9.

${ }^{30}$ Felten u. a. (Anm. 1:2004) 99 Abb. 2.
} 
Nordstraße und Annex

Bei dem südlichen, trapezförmigen Annex (Abb. 15) handelt es sich um einen sekundären Anbau, da in seinem Inneren auf einer Fläche von $1.50 \mathrm{~m}$ Länge und $1 \mathrm{~m}$ Breite noch Reste einer Pflasterung aus unregelmäßigen Andesitplatten freigelegt wurden, die in Material, Technik und Niveau $(+10.60 \mathrm{~m})$ der Pflasterung der bislang auf einer Länge von $7.50 \mathrm{~m}$ untersuchten Nordstraße genau entspricht. Es ist folglich damit zu rechnen, dass in einer ersten Erbauungsphase das Gelände südlich vor dem Nordbau von einem größeren gepflasterten Platzareal eingenommen worden war, welches bei Anlage des Annexes auf eine $1.70 \mathrm{~m}$ breite Pflasterstraße reduziert wurde. In Zusammenhang mit dem sekundären Einbau des Annexes ist auch die Anlage des unter der Nordstraße verlaufenden Kanals zu sehen. Zum einen ist die Pflasterung der Nordstraße in ihrer südlichen Hälfte wesentlich sorgfältiger verlegt, kleinsteinig ausgezwickt und gleichmäßig ansteigend nivelliert (von $+10.30 \mathrm{~m}$ auf $+10.70 \mathrm{~m}$ im Osten), während sie im Anschluss an die Kanalabdeckung eine auffällige Baunaht in Gestalt einer breiten, nur mit Erde gefüllten Fuge aufweist. Die Abdeckung des Kanals selbst ist grob und nachlässig verlegt, besteht partiell aus blockförmigen Spolien und besitzt eine sehr unregelmäßige, in großen Niveausprüngen verlaufende Oberseite. Ferner befinden sich in der südlichen Langseite des Annexes Andesitplatten der Pflasterung als Spolien zur Abgleichung der Lagerfugen verbaut.

Ein weiterer Pflasterrest wurde im direkten Anschluss an die östliche Grabungsgrenze zwischen Nordbau und Nordostbau freigelegt. Auf ihm bzw. in seinen Fugen fand sich hellenistische Reliefkeramik. Auch bei dieser Fläche könnte es sich um den verbliebenen Teil einer Platzpflasterung handeln, die sich dann offenbar bereits östlich der Ostwand des Nordbaus befindet, sofern für diesen nicht noch weitere, ostseitig anschließende Raumeinheiten zu veranschlagen sind.

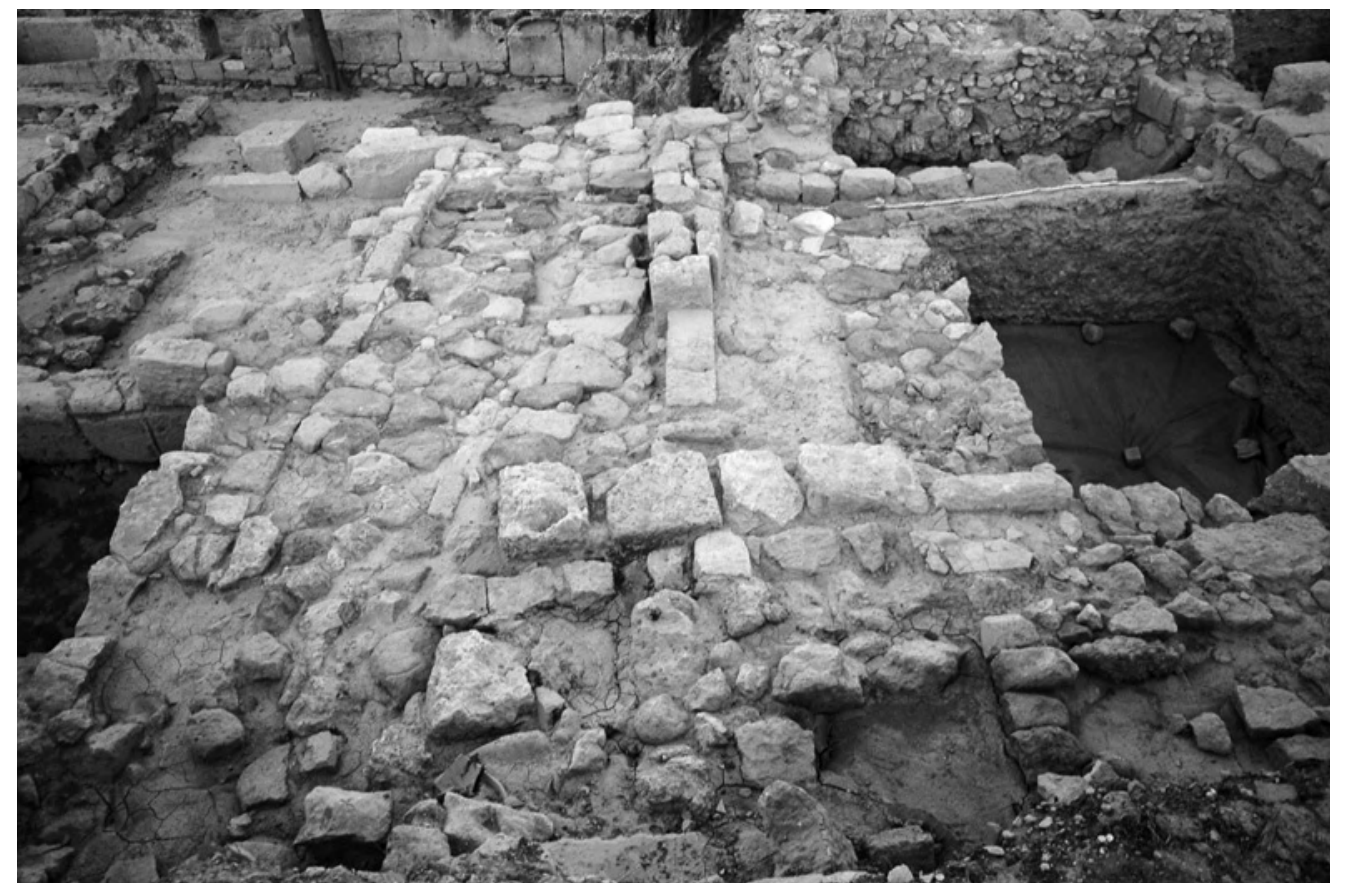

15 Nordstraße und Annex Nordbau. Ansicht von Osten 


\section{Nordostbau}

Auch im südöstlichen Bereich der durch die Grabung freigelegten Pflasterstraße ändern sich in der aufgedeckten Bausubstanz Material und Verlegetechnik auffallend. Die Pflasterung wird kleinsteiniger und ist von vielen Fehlstellen unterbrochen. Auch hier dürfte ein sekundärer Eingriff in die vorhandene Baumasse anzunehmen sein, der in Zusammenhang mit einer Veränderung des Nordostbaus steht. An diese ursprünglich $5 \mathrm{~m}$ lange und $4.30 \mathrm{~m}$ breite, einräumige Struktur (im Folgenden: Nordostbau, Raum I) wurde ostseitig ein zweites Raumkompartiment mit den Innenmaßen von $4.1 \mathrm{~m}$ auf $3 \mathrm{~m}$ angefügt (im Folgenden: Nordostbau, Raum II). Werkmaterial und Mauerungstechnik entsprechen im Wesentlichen der Bauweise des südlich an den Nordbau angesetzten Annexes, wobei sich an der Nordostecke des Raumes auch eine deutliche Baunaht abzeichnet. Im Inneren von Raum II, der partiell von einer byzantinischen Mauerecke überlagert ist und eine ovale Schuttgrube selber Zeitstellung enthielt, wurde in einem tieferen Stratum der aus zwei Porosblöcken bestehende Rest einer massiven Terrassenmauer mit nordsüdlicher Verlaufsrichtung festgestellt $(+10.00 \mathrm{~m})$. Die beiden sichtbaren, $90 \mathrm{~cm}$ langen und mindestens $50 \mathrm{~cm}$ hohen Blöcke sind rückseitig bruchrau belassen und besitzen die gleiche Ausrichtung wie das lange Analemma, an das sich die Anlagen von Ostbau 0-II anlehnen, allerdings um ca. $3.50 \mathrm{~m}$ nach Osten versetzt. Ob ein möglicher Zusammenhang zwischen beiden Terrassierungsanlagen besteht, soll im Rahmen der nächsten Kampagnen geklärt werden.

\section{Nordbau, Raum II}

Das ostseitig an Raum I des Nordbaus (vormalig >Schwellenbau $<$ ) anschließende Raumkompartiment Raum II - wurde in einer ca. $2.5 \mathrm{~m}$ Höhe umfassenden Tiefgrabung bis auf den gewachsenen Fels hinab untersucht (Abb. 16). Etwa $3.5 \mathrm{~m}^{2}$ der gesamten Innenraumfläche von $17.4 \mathrm{~m}^{2}$ sind im Bereich der Südwestecke von der byzantinischen Tonnenzisterne okkupiert, deren Mauerung die West- und Südwand von Raum II direkt abschneidet (Abb. 11). Die Zisterne wurde demnach als Schacht abgetieft und anschließend von innen her ausgemauert, wodurch sich an den Außenseiten keine nennenswerten Streifen einer Baugrube gebildet haben. Unter einem $60 \mathrm{~cm}$ dicken Stratum $(+11.14-10.46 \mathrm{~m})$ mit byzantinischer Keramik erschien in Raum II eine feste, hellbraune Erdschicht (+10.46-10.21 m), die abgesehen von zwei byzantinischen ke-

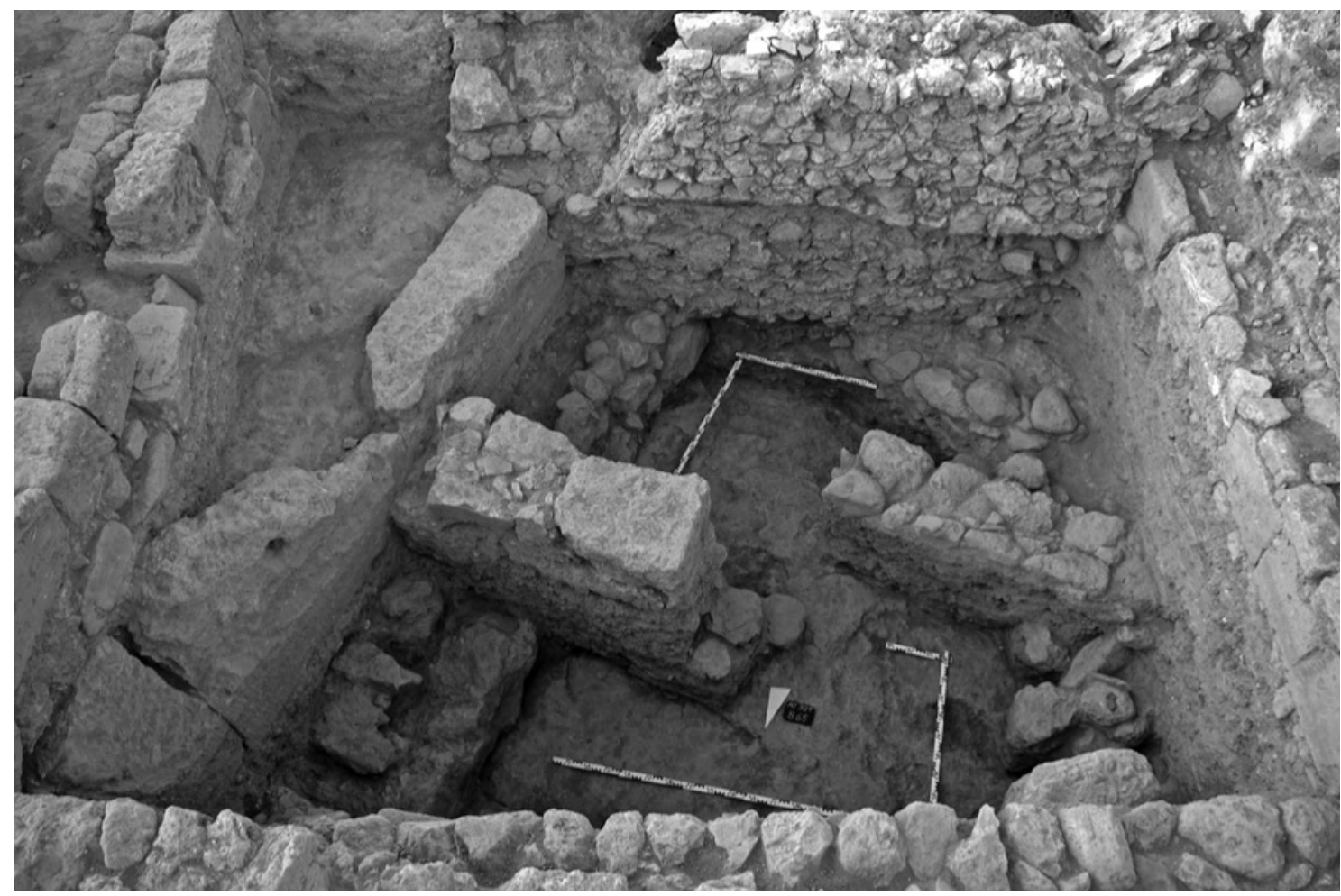

16 Nordbau. Raum II. Baubefund nach Abschluss der Untersuchungen. Ansicht von Norden 
ramischen Einsprengseln nur noch hellenistisches Fundmaterial enthielt. Gleichzeitig ließ sich in einem Abstand von $4.25 \mathrm{~m}$ von der Ostwand des Raumes I (vormals >Schwellenbau<) ein parallel verlaufender Mauerzug feststellen $(\mathrm{OK}+10.86 \mathrm{~m}$; UK $+10.17 \mathrm{~m})$. Damit besitzen, wie bereits angeführt, Raum I und II des Nordbaus identische Ausmaße. Im Zuge der Arbeiten konnte zunächst am Nordende von Raum II eine Weiterführung des Verlaufs der Rückwand von Raum I nach Osten festgestellt werden. Im Gegensatz zu der dort eingesetzten Spolienbauweise handelt es sich hierbei jedoch um eine lediglich einlagige Anordnung unregelmäßiger, flacher Feldsteine. Ferner zieht die in den oberen Lagen festgestellte Erdschicht $(+10.46-10.21 \mathrm{~m})$ über diese >Rollierung \hinweg. Für Raum II muss generell mit einem wesentlich höheren Fußbodenniveau gerechnet werden, da die rückseitige Rollierung mit ihrer Oberkante bereits $60 \mathrm{~cm}$ über dem Laufniveau von Raum I (+9.40 m) liegt.

Diese Erdschicht in Raum II verläuft über einem grauen Fußbodenestrich $(+9.94 \mathrm{~m})$, der über den größten Teil der Fläche von Raum II verfolgt werden konnte. Nur in der östlichen Hälfte ließen sich die Spuren einer Ausrissgrube im Bereich der Nordostecke der Zisterne identifizieren; nördlich dieser Störung war der graue Estrich nicht mehr nachweisbar. In dem offenbar gestörten Streifen fanden sich Fragmente einer Transportamphora mit gestempeltem Henkel (Abb. 17, 2).

$\mathrm{Zu}$ den Funden auf diesem Fußboden zählen in der Westhälfte von Raum II Fragmente von Westabhang-Ware und eine nahezu komplette teilgefirnisste Olpe (Abb. 17, 1). Besonders hervorzuheben sind die Reste zweier farbig gefasster und partiell vergoldeter weiblicher Terrakottastatuetten (Abb. 18, 1-2) 31. $^{31}$. Bei einem Stück (Abb. 18, 2) handelt es sich um die $15 \mathrm{~cm}$ hohe, untere Hälfte einer Gewandstatuette. Die hohle Figur ist aus einem kräftig rostroten Ton
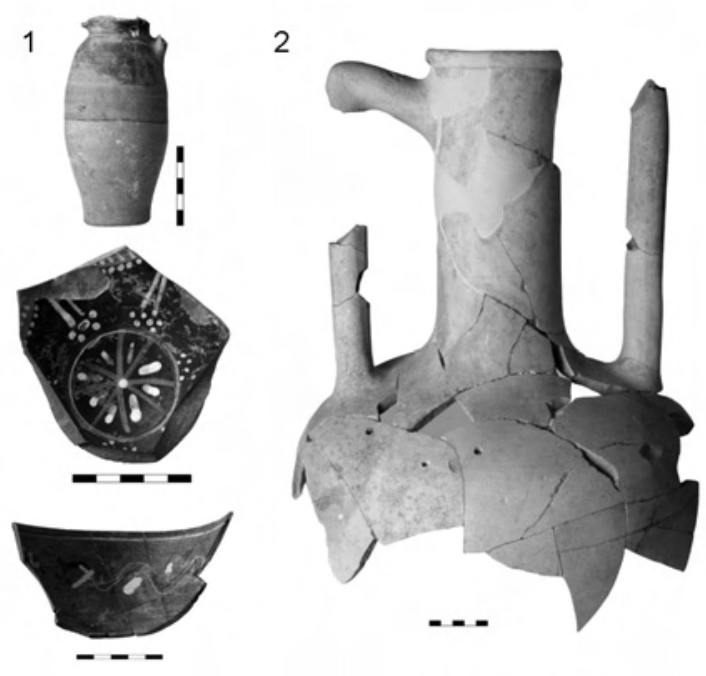

17 Nordbau. Raum II. Keramik auf Fußboden +9.94 m (1) und aus der Störung (2). Auswahl geformt $^{32}$. Sie steht frei auf einer manschettenförmig auskragenden, flachen Standplatte mit leicht angewinkeltem rechten Spielbein und trägt einen dünnen, bodenlangen Chiton, welcher die Spitze des linken Standbeinfußes freigibt. Der Chiton ist weiß gehalten; der Saum ist mit einem blauen Band und einem rosafarbigen Abschlussstreifen verziert. Das Himation ist über einer weißen Grundierung hellblautürkis bemalt und besitzt eine $2 \mathrm{~cm}$ breite, rosa bemalte Abschlussbordüre mit zwei weißen Seitenstreifen. Der als markanter tordierter Wulst gestaltete obere Himationrand verläuft bogenförmig um die rechte Hüfte und wurde ursprünglich über dem vorgestreckten linken Unterarm gehalten ${ }^{33}$. An der linken Körperseite fällt er mit einer S-förmig gewundenen Saumkante vertikal herab. Das Faltenmotiv des Gewandes, durch welches sich das rechte Knie leicht durchdrückt, erscheint reich bewegt und plastisch durchgeformt.

Für die zweite Figur $(A b b .18,1)$ lässt sich trotz nicht anpassender Oberkörperpartie eine Höhe von etwa $35 \mathrm{~cm}$ erschließen. Nach den Spuren in den Bereichen der beiden Seitenkanten wurde sie aus zwei Halbschalenmatrizen geformt und in der Partie der Bauch- und Hüftfalten sekundär mit einem Stilus nachbearbeitet. Es handelt sich um eine stehende weibliche Gewandfigur, die sich mit der linken Hüfte an einen schmalen Pfeiler lehnt. Das Körpergewicht ruht überwiegend auf dem rechten Bein, welches von dem leicht abgewinkelten linken Bein gekreuzt wird. Die rechte Hüftpartie biegt sich nach außen. Die linke Schulter ist hochgereckt, nach dem erhaltenen Halsansatz war der Kopf nach rechts gewendet. Der rechte Arm führte

\footnotetext{
${ }^{31}$ Für Hinweise wird D. Graepler (Göttingen) und C. Blume (Freiburg) gedankt.

${ }^{32}$ L. Burn - R. Higgins, Catalogue of Greek terracottas in the British Museum III (London 2001) Taf. 2, 2271 (Myrina).

${ }^{33}$ Motiv: S. Besques, Catalogue raisonné des figurines et reliefs en terre-cuite grecs, étrusques et romains III 1 (Paris 1971) Taf. 28; Burn - Higgins (Anm. 32) 178 Nr. 2504 Taf. 84; Motiv in der Großplastik vgl. LIMC V 2 (1990) 388 s. v. Hygieia (F. Croissant).
} 


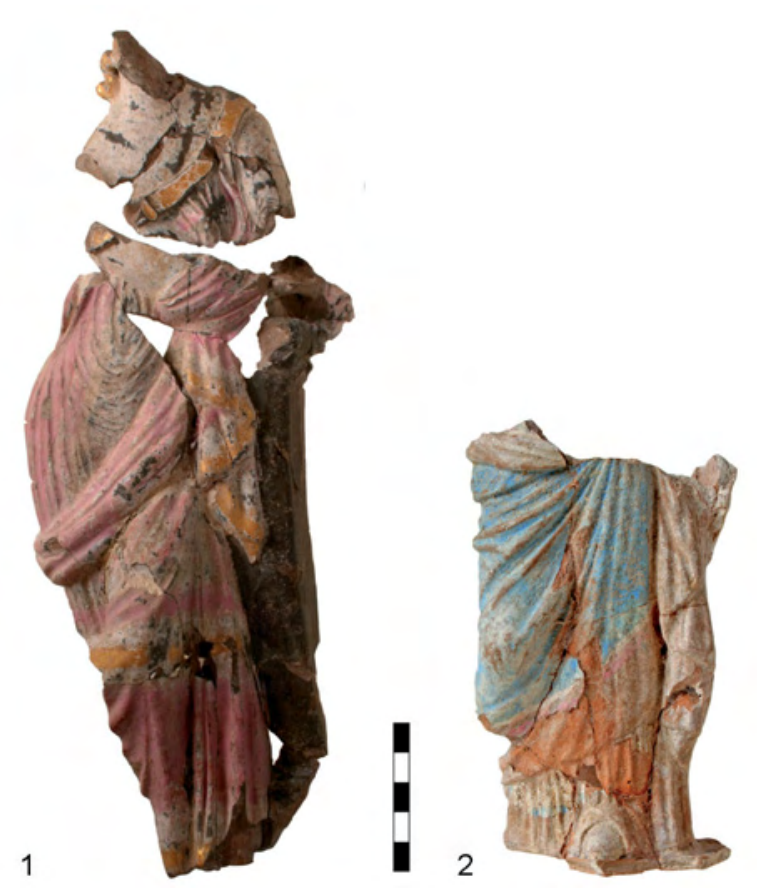

18 Nordbau. Raum II. Fragmente von Terrakotten auf Fußboden $+9.94 \mathrm{~m}$ bei stark abfallender rechter Schulter in Höhe der Brustgürtung eng am Körper vorbei nach rechts; Unterarm und Handgelenk lagen wohl auf dem Pfeiler auf. Der linke Arm dürfte stärker angewinkelt gewesen sein. Der feingemagerte, leicht seifig wirkende Ton ist von kräftig dunkelbrauner Farbe $^{34}$, die nackten Körperpartien sind mit einem cremeweißen Überzug versehen. Als Untergewand trägt die Figur einen langen, rosafarbenen Chiton mit schmalen plissierten, nachbearbeiteten Falten. Als Träger dient ein stegförmig erhöhtes Brust- und Schulterband mit Blattvergoldung ${ }^{35}$. An der rechten Schulterpartie ist der Träger des Chitons nach unten gerutscht und kommt in Höhe des Oberarmes zu liegen. Ein ebenfalls rosafarbenes Himation bedeckt den größten Teil des Unterkörpers. Sein oberes Ende verläuft als markanter Wulst unter der ausbiegenden rechten Hüfte in einem engen Bogen nach oben, wo es um Ellenbogen und Unterarm gewickelt ist und in der Folge als zickzackförmige Saumspitze nach unten hängt. Zusätzlich zur rosaroten Bemalung ist das Himation in Kniehöhe mit einem $2 \mathrm{~cm}$ breiten, von zwei weißen Streifen eingefassten, goldenen Band verziert; den unteren Abschluss bildet ein 1,5 cm breiter, weißgoldener Saum. Ebenfalls vergoldet ist ein lockenförmiger Ansatz im Genick der Figur.

Die Darstellung einer seitlich an einen Pfeiler oder eine Miniatursäule angelehnten weiblichen Gewandfigur ist in der hellenistischen Terrakottaplastik kein ungewöhnliches Motiv ${ }^{36}$; meist sind die Figuren mit dem Ellenbogen oder dem Unterarm auf der Pfeileroberseite aufgestützt. Seltener ist dagegen die an der äginetischen Terrakotta zu beobachtende Kombination des überkreuzten, angelehnten Standmotivs mit der markanten Haltung des Oberkörpers und seiner Extremitäten, die mehrere unterschiedliche Motive in sich vereinigt. Der eng am Oberkörper anliegende, nach rechts übergreifende Arm ist bei gänzlich verhüllten Mantelfiguren bekannt ${ }^{37}$, und auch das Motiv des auf den Oberarmansatz verrutschten Chitonsaumes bei Freigabe der rechten Schulter zählt zu beliebten >aphrodisisch-erotischen A Anspielungen in der weiblichen Figuralplastik $^{38}$. Das enge seitliche Übergreifen des rechten Armes sowie der angewinkelte linke Arm lassen sich möglicherweise auch mit der Armhaltung der Aphrodite von Capua in Zusammenhang bringen ${ }^{39}$, auch wenn hinsichtlich der übrigen Darstellungsdetails - dem nackten Oberkörper wie auch dem aufgesetzten linken Bein - motivische Differenzen bestehen. Das Haltungsmotiv der äginetischen Terrakotta könnte eine

\footnotetext{
${ }^{34}$ Burn - Higgins (Anm. 32) Taf. 3 Nr. 2416 (Priene).

${ }^{35}$ Erhöhtes Trägerband auch bei einer Terrakotta aus Priene; F. Rumscheid, Die figürlichen Terrakotten von Priene. Fundkontexte, Ikonographie und Funktion in Wohnhäusern und Heiligtümern im Licht antiker Parallelfunde (Wiesbaden 2006) Taf. 47, 3.

${ }^{36}$ D. Graepler, Tonfiguren im Grab. Fundkontexte hellenistischer Terrakotten aus der Nekropole von Tarent (München 1997$) 110$. 117 mit Anm. 256 Abb. 60 »angelehnte Aphrodite (?)«; S. Besques, Catalogue raisonné des figurines et relief en terre-cuite grecs, étrusques et romains II (Paris 1963) Taf. 25. 30. 140; Rumscheid (Anm. 35) Taf. 47, 3; 48.

${ }^{37}$ M. Bieber, The sculpture of the Hellenistic Age (New York 1961) Abb. 602; Besques (Anm. 33) Taf. 30, D 138; Burn - Higgins (Anm. 32) 75 f. Taf. 29 Nr. 2158.

${ }^{38}$ Besques (Anm. 36) Taf. 25, a-LY 1606. c-Bo 147. e-MYR 629; 131, b-MYR 226, im Bewegungsmotiv; P. G. Leyenaar-Plaisier, Les terres cuites Grecques et Romains. Catalogue de la collection du Musée national des Antiquités à Leiden III (Leiden 1979) Taf. 97 Nr. 683. Sogar im Kampfgetümmel der Gigantomachie ist Aphrodite mit diesem Detail ausgezeichnet; vgl. W. D. Heilmeyer, Der Pergamonaltar (Tübingen 1997) $88 \mathrm{f}$.

${ }^{39}$ T. Hölscher, Die Victoria von Brescia, AntPl 10 (Berlin 1970) 67-79; H. Knell, Die Aphrodite von Capua und ihre Repliken,
} AntP1 22 (München 1993) 117-139. 
Variante des bekannten >Pudicitia-Typus wiedergeben ${ }^{40}$, wobei die Hand des angewinkelten linken Armes einen Fächer oder einen Handspiegel gehalten haben mag. Hierfür spricht auch der stark nach rechts gewendete Halsansatz ${ }^{41}$.

Für die partiell vergoldete Terrakotta scheint eine zeitliche Stellung kurz nach der Mitte des 2. Jahrhunderts v. Chr. wahrscheinlich, das zweite Exemplar dürfte aufgrund der feinteiligeren, filigran geformten Gewandfaltung etwas früher anzusetzen sein; es gehört möglicherweise noch dem früheren 2. Jahr-
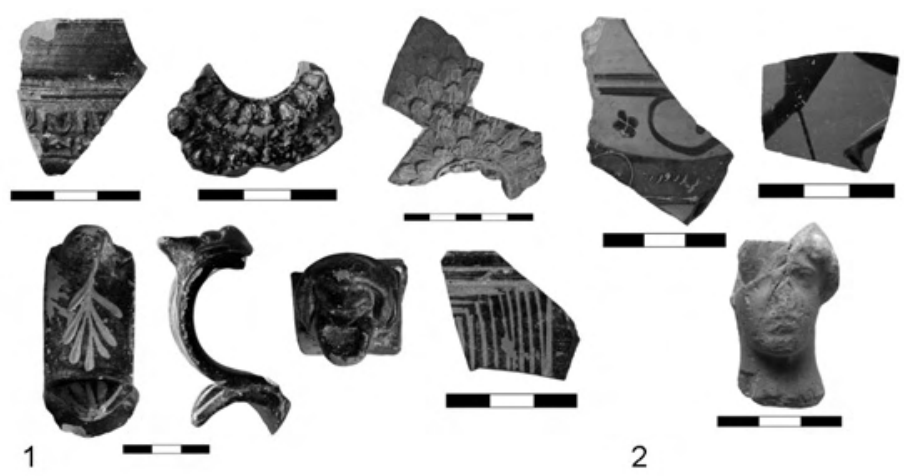

19 Nordbau. Raum II. Hellenistische Keramik (1) und älteres Fundmaterial (2) aus Fußboden +9.94 m. Auswahl

hundert v. Chr. an ${ }^{42}$.

Die zeitliche Stellung des Bodens, auf dem die Terrakotten lagen, wird durch die in ihm und in seiner Unterfüllung befindliche Keramik, darunter qualitätsvolle Reliefbecher und applikenverzierte WestabhangWare, bestimmt (Abb. 19, 1). Zu älteren Funden dieses Stratums zählen archaische schwarzfigurige Keramik, klassische Stempelware und der Kopf einer weiblichen Terrakotta (Abb. 19, 2). Die Füllung des oberen Bodens verläuft über einer tieferen Lauffläche $(+9.75 \mathrm{~m})$, greift dabei aber auch durch zahlreiche Gruben in sie ein. Eine weitere größere Störung sowie Reste der früheren Bebauung ließen sich dabei im Bereich des östlichen Endes und in der Nordostecke von Raum II bereits in höheren Lagen feststellen. Hier kam im Zuge der Arbeiten der $4 \mathrm{~m}$ lange Rest der massiven Orthostatenmauer zutage, welche den nördlichen, leicht spitzwinkelig abführenden, weiteren Verlauf des großen Orthostaten- und Quaderverbandes am Nordende des Kernbaus bildet (Abb. 16). Der Mauerrest in Raum II verläuft Nord-Süd und fluchtet mit der an der Südostecke befindlichen Orthostatenwange, an die sich westseitig ein zweifach gestufter Treppenblock anschließt (Abb. 1). Dieser Zugang führt auf das östlich des Kernbaus verlegte Hofpflaster klassischer Zeitstellung $(+9.08 \mathrm{~m})$. Eine an der Innenseite der Orthostatenwange angebrachte, vertikale Einfalzung belegt aber, dass der große Orthostatenverband an dieser Stelle ursprünglich geschlossen gewesen war und die Anlage der Zugangstreppe wohl im Zusammenhang mit der Pflasterung des Hofes zu sehen ist. Mit dieser sekundären Veränderung ist wohl auch ein 1.40 m langer, grobsteiniger Mauerzug zu verbinden, der zu einem am Südende, durch die Zisterne zerstörten, kleinen Eingangsbau gehört haben könnte ${ }^{43}$.

Während die südliche Hälfte des Orthostatenverbandes in Raum II vom hellenistischen Fußboden (+9.94 m) überzogen wird, muss der nördliche Teil aufgrund seines Oberkantenniveaus $(+10.15)$ sichtbar gewesen sein. Der Orthostat ist oberseitig stark abgewittert sowie durch zwei Bothroi an West- und Ostseite, welche auch durch die tiefere Lauffläche $(+9.75 \mathrm{~m})$ stoßen, trichterförmig abgeschlagen. Im Bereich der Nordostecke sitzt die Ostwand von Raum II direkt auf dem Orthostaten auf. Unter dieser Lauffläche, die aufgrund der Keramik in das 5. Jahrhundert v. Chr. zu datieren ist, verläuft ein tieferer Fußboden $(+9.57 \mathrm{~m})$, der an den Orthostatenverband heranführt. Die speziell in der südlichen Hälfte in ihm befindliche Schicht aus

\footnotetext{
${ }^{40}$ Zum >Pudicitia-Typus`vgl. G. Kleiner, Tanagrafiguren. Untersuchungen zur hellenistischen Kunst und Geschichte (Berlin 1942) 160-165; L. Alscher, Griechische Plastik IV (Berlin 1957) 115-118; A. Linfert, Kunstzentren hellenistischer Zeit. Studien an weiblichen Gewandfiguren (Wiesbaden 1976) 147-156.

${ }^{41}$ Eine andere mögliche Ergänzung, dass nämlich die Terrakotta wie die Aphrodite von Capua einen Schild gehalten hat, scheint durch die Ansätze der Armhaltung schwierig, auch wenn dieser möglicherweise dekorativ verkleinert dargestellt war; vgl. L. Balensiefen, Die Bedeutung des Spiegelbildes als ikonographisches Motiv in der antiken Kunst (Tübingen 1990) Taf. 19. 46; zum Vorbild und dem Aufstellungsort des großplastischen Urbildes der Aphrodite von Capua: Knell (Anm. 39) 129-133.

42 Rumscheid (Anm. 35) 443 f. Nr. 115 Taf. 47, 3; Nr. 117 Taf. 48, 1-3; für das ältere Exemplar Rumscheid (Anm. 35 ) 441 Nr. 107 Taf. 43, 1-2; Burn - Higgins (Anm. 32) 75-76 Nr. 2158 Taf. 29.

${ }^{43}$ Solche doppelten Zungenmauern an kleinen Torbauten in Delos, F. Robert, Trois sanctuaires sur le rivage occidental. Dioscurion, Asclépiéion, sanctuaire anonyme (Leucothion?), Délos 20 (Paris 1952) 8 Abb. 4, oder in Attika, O. Dally, Kulte und Kultbilder der Aphrodite in Attika im späteren 5. Jahrhundert vor Christus. Zu einem Fragment im Athener Akropolismuseum, JdI 112, 1997, 6 Abb. 2.
} 

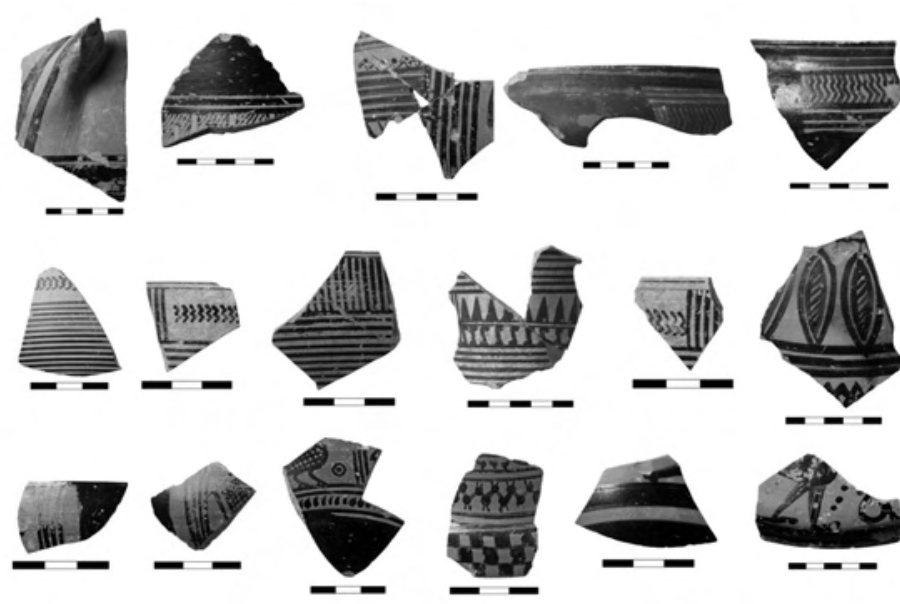

20 Nordbau. Raum II. Keramik aus archaischem Fußboden +9.57 m. Auswahl
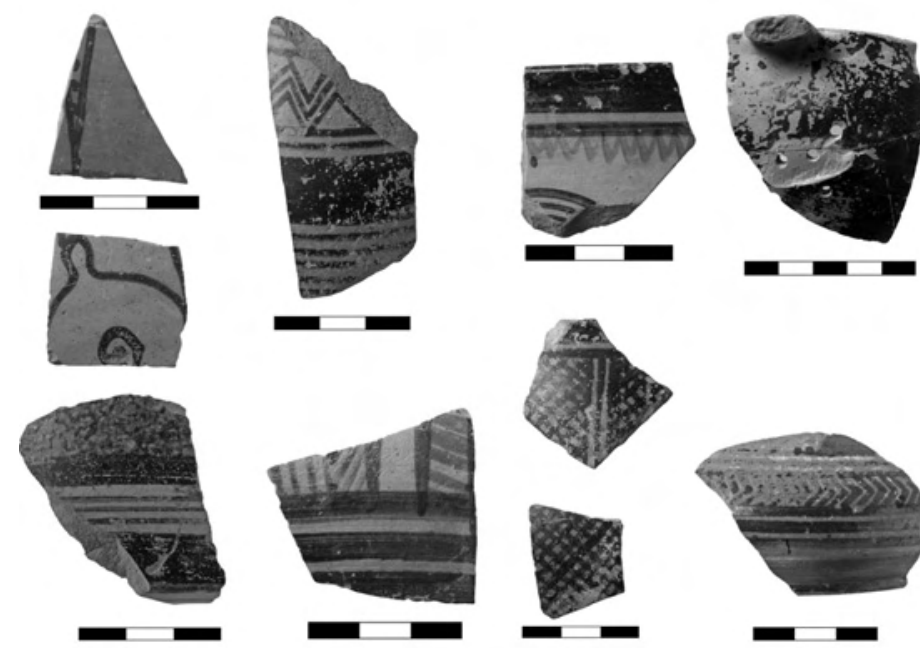

21
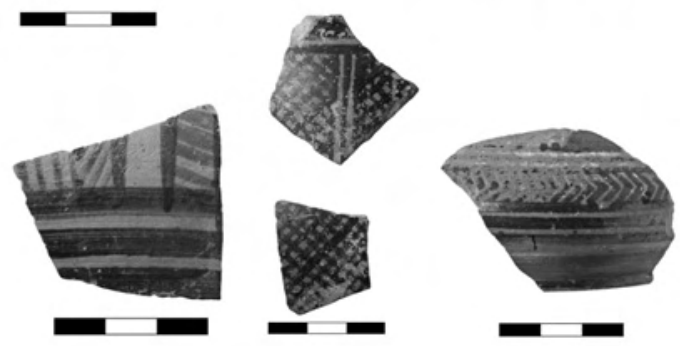

21 Nordbau. Raum II. Keramik aus früheisenzeitlichem Nutzungshorizont +9.15 m. Auswahl
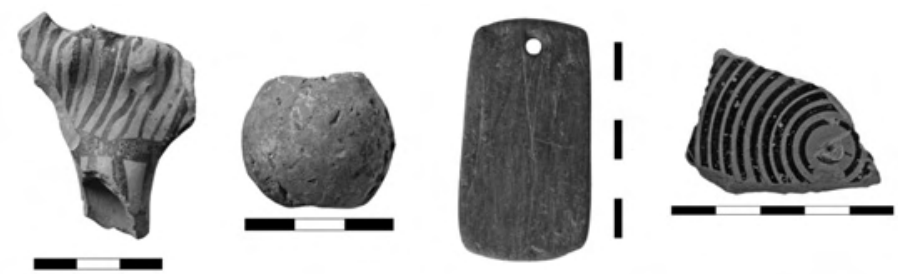

22 Nordbau. Raum II. Fundmaterial aus tiefstem Stratum. Auswahl kleinformatigem Porossplitt belegt, dass dieser Boden mit der Errichtung der Orthostaten zu verbinden ist. Das keramische Fundmaterial enthielt neben vereinzelten protogeometrischen und geometrischen Scherben attische, korinthische und ostionische Keramik des 7. und 6. Jahrhunderts v. Chr., deren späteste Vertreter die Datierung der Orthostatenanlage in spätarchaische Zeit bestätigen (Abb. 20).

Unter der archaischen Auffüllung ließ sich auf tieferem Niveau ein Nutzungshorizont identifizieren $(+9.15 \mathrm{~m})$, der neben wenigem mykenischen Material ausschließlich protogeometrische und geometrische Keramik enthielt (Abb. 21), und mit dem sich möglicherweise auch bauliche Strukturen verbinden lassen. Dabei handelt es sich um einen $1.50 \mathrm{~m}$ langen Mauerzug (+9.30 m), der unter der Westwand von Raum II hervortritt und nach Osten verläuft (Abb. 16), sowie um eine südlich davon befindliche, gebogene Steinsetzung (+9.19 m).

Abgeschlossen wird die stratigraphische Abfolge unter Raum II von einem direkt auf dem Fels verlaufenden Stratum $(+8.73 \mathrm{~m})$, das insbesondere in der südlichen Raumhälfte starke Brandeinwirkung aufwies und neben wenigem protogeometrischen Material mykenisches Fundgut, darunter ein Psi-Idol, Spinnwirtel sowie einen Schleifstein aus Schiefer, enthielt (Abb. 22). Ebenfalls auf dem Fels aufsitzend fand sich eine starke, Nord-Süd verlaufende Mauer $(\mathrm{OK}+9.08 \mathrm{~m})$. Ihre Ausrichtung entspricht exakt der des unmittelbar östlich von ihr befindlichen, auf höherem Niveau errichteten Orthostatenverbandes (Abb. 16).

Abschließend wurde in einer kleinen Felseinsenkung älteres Material, darunter FH II-zeitliche Keramik und möglicherweise auch neolithische Ware, freigelegt.

\section{Nordbau, Raum III}

Östlich von Raum II konnte der anschließende Raum III in der Kampagne 2007 nur etwa zur Hälfte in seinen oberen Straten untersucht werden (Abb. 10). Das Fundament seiner nördlichen Rückwand ließ sich zunächst bis zu einer Länge von $2.30 \mathrm{~m}$ feststellen. Im Gegensatz zur einfachen Rollsteinlage von Raum II besteht hier die Rückwand aus dicht gelegten Bruchsteinen und Spolienfragmenten und entspricht in der 
Bautechnik damit der Rückwand von Raum I. Möglicherweise weist dieser markante Unterschied in Werkmaterial und Verlegetechnik auf eine ursprünglich offene Hofgestaltung von Raum II hin, der in einer früheren Phase von den Räumen I und III eingeschlossen war. $\mathrm{Zu}$ einer späteren Gestaltung von Raum III gehört eine nach Osten verlaufende, zweischalige Mauer, die in Technik und Material dem Annex südlich des Nordbaus ähnelt. Die Südwand von Raum III ist aus Spolien errichtet und besitzt eine mittig verlegte, $90 \mathrm{~cm}$ lange Schwellplatte (+10.69 m), während im östlichen Anschluss daran der Verlauf durch die byzantinische Verbauung wiederum verunklärt ist (Abb. 15). Aufgrund der Schwellplatte ist für das Laufniveau in Raum III gegenüber Raum I (+9.40 m) und II (+9.94 m) eine nochmalige Erhöhung des Fußbodens anzunehmen (ca. $+10.60 \mathrm{~m}$ ). Bezüglich der Ostwand von Raum III können noch keine abschließenden Aussagen getroffen werden. Hier liegen die Reste der byzantinischen Bebauung teilweise unmittelbar auf der antiken Baumasse ${ }^{44}$, teilweise greifen sie tief ein und haben die hellenistischen Mauerzüge sogar ersetzt. Es ist damit zu rechnen, dass bei Anlage der nachantiken Gebäude ältere Bausubstanz in ihren Ausrichtungen mitbenutzt worden ist.

Nördlich der Rückmauer von Raum III ließ sich die Fortsetzung der massiven Orthostatenstruktur unter Raum II feststellen. Sie besteht aus einem bis zur Grabungsgrenze verlaufenden, rückseitig bruchrau belassenen Porosblock (OK $+10.04 \mathrm{~m}$ ), der vermutlich die Unterlage für den in diesem Bereich ansteigenden Orthostatenverband gebildet hat.

\section{Annex Nordbau}

Im südseitig an den Nordbau anschließenden trapezförmigen Annex wurde eine Sondage angelegt. Die untersuchte Teilfläche bestand im obersten Stratum aus einer $50 \mathrm{~cm}$ starken, dicht mit Keramik und Ziegelschutt durchsetzten Auffüllungsschicht $(+10.68 \mathrm{~m})$, die der Pflasterung des Vorplatzes, auf welcher der Annex errichtet wurde, vorausgegangen war. Die Füll-

\footnotetext{
${ }^{44}$ So befindet sich in der Ostwand eine $1.10 \mathrm{~m}$ lange Schwellplatte auf einem Niveau von $+11.37 \mathrm{~m}$ verbaut.
}

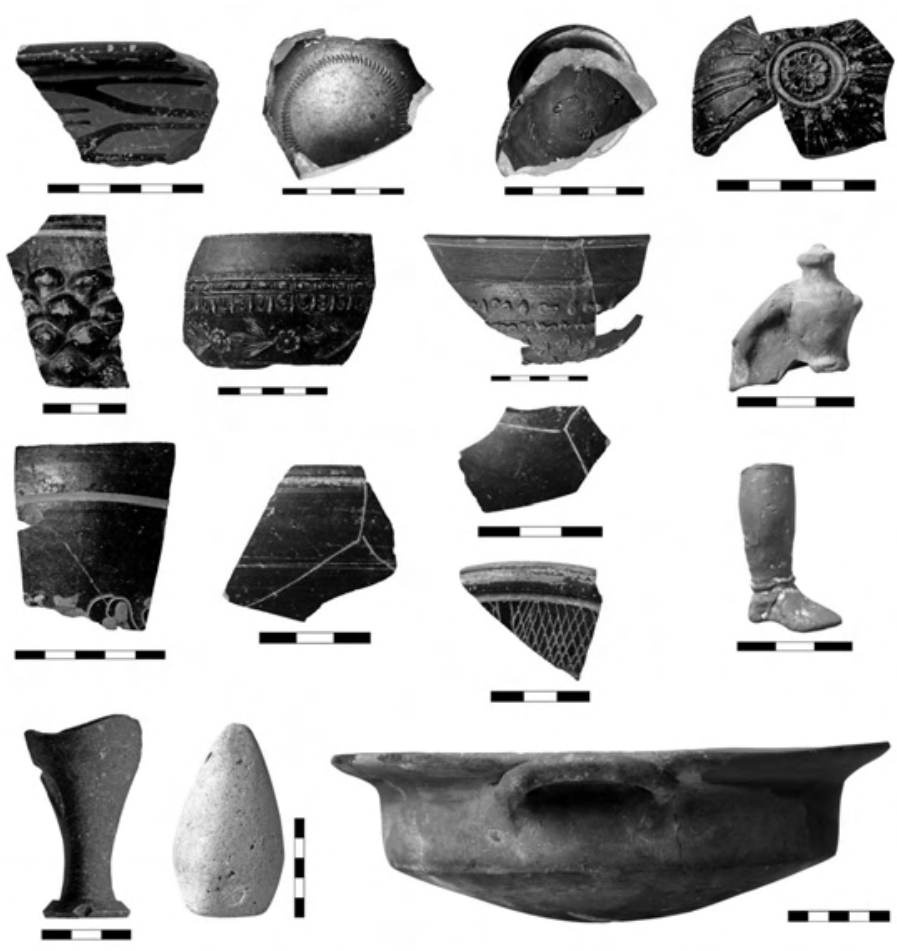

23 Nordbau. Annex. Keramik und Kleinfunde aus hellenistischer Schuttschicht. Auswahl
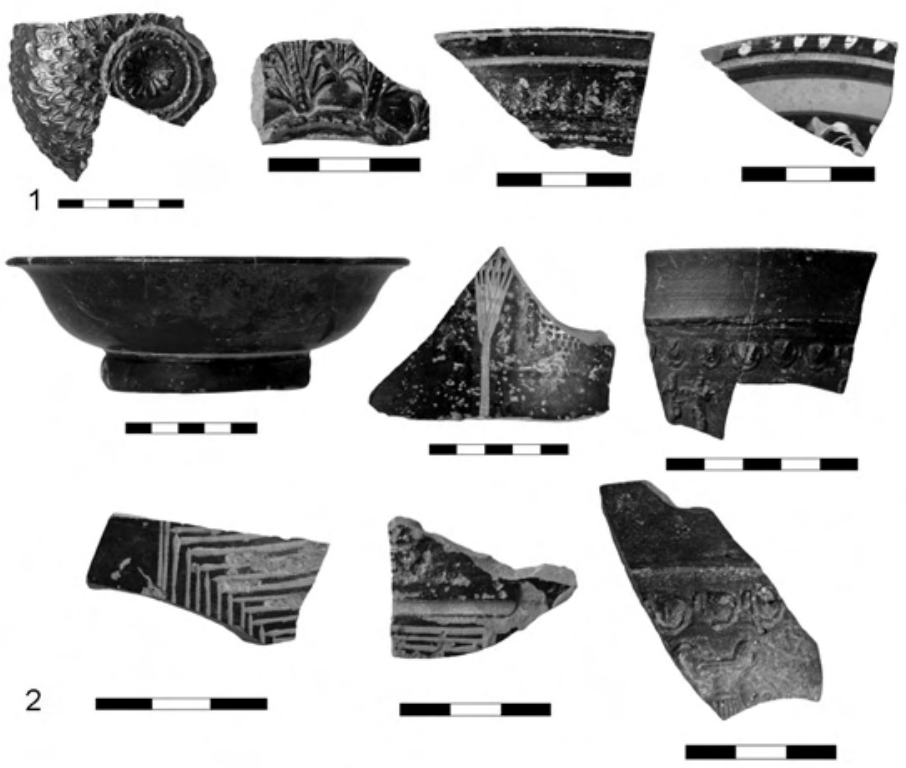

24 Nordbau. Annex. Hellenistische Keramik aus Bothros und Störung. Auswahl 
schicht enthielt Fragmente rotfiguriger Gefäße, klassische bis hellenistische, z. T. stempelverzierte Schwarzfirnissware, Schwarzfirnisslampen, Bruchstücke von Terrakotten, Fragmente von Westabhang-Ware und Reliefbechern sowie unverzierte Schüsseln, Unguentarien, Lopaden und ein gestempeltes Webgewicht (Abb. 23); das Material ist hier bereits in stark zerscherbtem Zustand eingebracht worden. Die Auffüllung verläuft über einem festgetretenen, braunen Laufhorizont $(+10.13 \mathrm{~m})$, in dessen Südostecke sich ein eingetiefter Bothros befand, der bis zu seiner Sohle ebenfalls hellenistische Reliefkeramik und Westabhang-Ware enthielt (Abb. 24, 1). Ein entsprechendes keramisches Spektrum ließ sich auch in einer sekundären Störung im Südwesten der Grabungsfläche feststellen (Abb. 24, 2).

Im Folgenden wurde die Grabungsfläche in vier Abhüben um eine Tiefe von ca. $90 \mathrm{~cm}$ abgesenkt, wobei sich hier weder bauliche Strukturen noch klare Bodenhorizonte abzeichneten. Erst auf einem tieferen Stratum (+9.26-9.23 m) zeigte sich eine etwas festere, braungraue Oberfläche, die von Norden nach Süden leicht abfällt und möglicherweise eine hypäthrale Lauffläche darstellt. Während das keramische Material der oberen beiden Abhübe von der klassischen Zeit bis in den Hellenismus reicht, darunter attisch rotfigurige Fragmente, Schwarzfirnissware (Riefelkännchen), Westabhang-Ware und Reliefbecher, war in den tieferen Straten der untersuchten Fläche keine hellenistische Ware mehr anzutreffen. Unter der erwähnten Lauffläche erschien in der südlichen Hälfte der Grabungsfläche ein Nutzungshorizont mit Steinverfüllung sowie Brand- und Aschenspuren ( $+9.16 \mathrm{~m})$, zu dem möglicherweise eine in der Nordostecke freigelegte, runde Steinsetzung $(\mathrm{OK}+9.22 \mathrm{~m})$ gehört. Diese Verfüllung setzte sich bis zum Ende der Grabungsarbeiten fort (Abschluss bei $+9.00 \mathrm{~m}$ ).

Die vollständige Erfassung des Areals `Nordbau<, seines südlichen Annexes und der darunter befindlichen Nutzungshorizonte sowie der massiven Terrassenmauer unter dem Nordostbau wird zu den vordringlichen Zielen der Kampagne des Folgejahres 2008 gehören.

\section{Areal \Südhügel}

Die Arbeiten am sog. Südhügel von Ägina-Kolonna konzentrierten sich 2007 auf die Grabungsflächen in den Quadranten Q2, Q5, Q6 und Q7 (Abb. 25) ${ }^{45}$. Ziel der Grabungen war es, den Grundriss des sog. Großsteinbaus (im Folgenden: GSB), dem wichtigsten Gebäude der Mittleren Bronzezeit, weiter freizulegen und seine Ausdehnung und die Abfolge seiner Bauphasen zu klären ${ }^{46}$. Dabei konnten zahlreiche stratigraphische Beobachtungen, vor allem zur mittelbronzezeitlichen Bauabfolge, gemacht werden. Größere Teile des GSB sowie der Schichtenabfolge sind allerdings durch die klassische bis spätrömische bzw. die byzantinische Bebauung zerstört worden. Bereits im Frühjahr 2007 wurden mit Unterstützung von INSTAP die archäozoologischen und archäobotanischen Untersuchungen (Projekt $>$ Aegina Kolonna. Subsistence and More $`$ ) fortgesetzt ${ }^{47}$.

\section{Quadrant Q2 (Abb. 25, Bereich D, E)}

Im Grabungsbereich D wurde vom GSB vor allem der östliche Teil des Hauptraumes mit der Nord-Süd orientierten Begrenzungsmauer ergraben. Die obersten Schichten waren durch die spätrömisch-byzantinische

45 Zur Methode s. Felten u. a. (Anm. 1:2003) 56.

${ }^{46}$ Zum GSB s. Felten u. a. (Anm. 1:2003) 60-61; Felten u. a. (Anm. 1:2004) 124-126; Felten u. a. (Anm. 1:2005) 30-35; Felten u. a. (Anm. 1:2006) 30-36; Felten u. a. (Anm. 1:2007) 110-119; W. Gauß, Minos auf Ägina - Beobachtungen zu den Beziehungen Äginas zu Kreta, in: E. Czerny u. a. (Hrsg.), Timelines. Festschrift Manfred Bietak II (Wien 2006) 435-446; W. Gauß R. Smetana, Aegina Kolonna, the Ceramic Sequence of the SCIEM 2000 Poject, in: F. Felten - W. Gauß - R. Smetana (Hrsg.), Ägina-Kolonna. Forschungen und Ergebnisse I: Middle Helladic Pottery and Synchronisms (Wien 2007) 63-65. 76-77; W. GaußR. Smetana, Aegina and the Cyclades, in: N. Brodie u. a. (Hrsg.), Horizon. A Colloquium on the Prehistory of the Cyclades, 25-28 March 2004, McDonald Institute of Archaeological Research (Cambridge 2008) 377 f.; W. Gauß - R. Smetana, Aegina Kolonna in the Middle Bronze Age, in: G. Touchais u. a. (Hrsg.), MESOHELLADIKA. The Greek Mainland in the Middle Bronze Age. Proceedings of the International conference, Athens, 8-12 March 2006, BCH Suppl. (in Druck).

${ }^{47}$ Das Projekt wird von G. Forstenpointner, A. Galik und G. Weißengruber (archäozoologische Analysen), U. Thanheiser (archäobotanische Analysen), K. Grossschmidt und F. Kanz (anthropologische Untersuchungen) gemeinsam mit W. Gauß und R. Smetana durchgeführt; s. dazu auch die in Druck befindlichen Vorberichte in: Touchais (Anm. 46). 


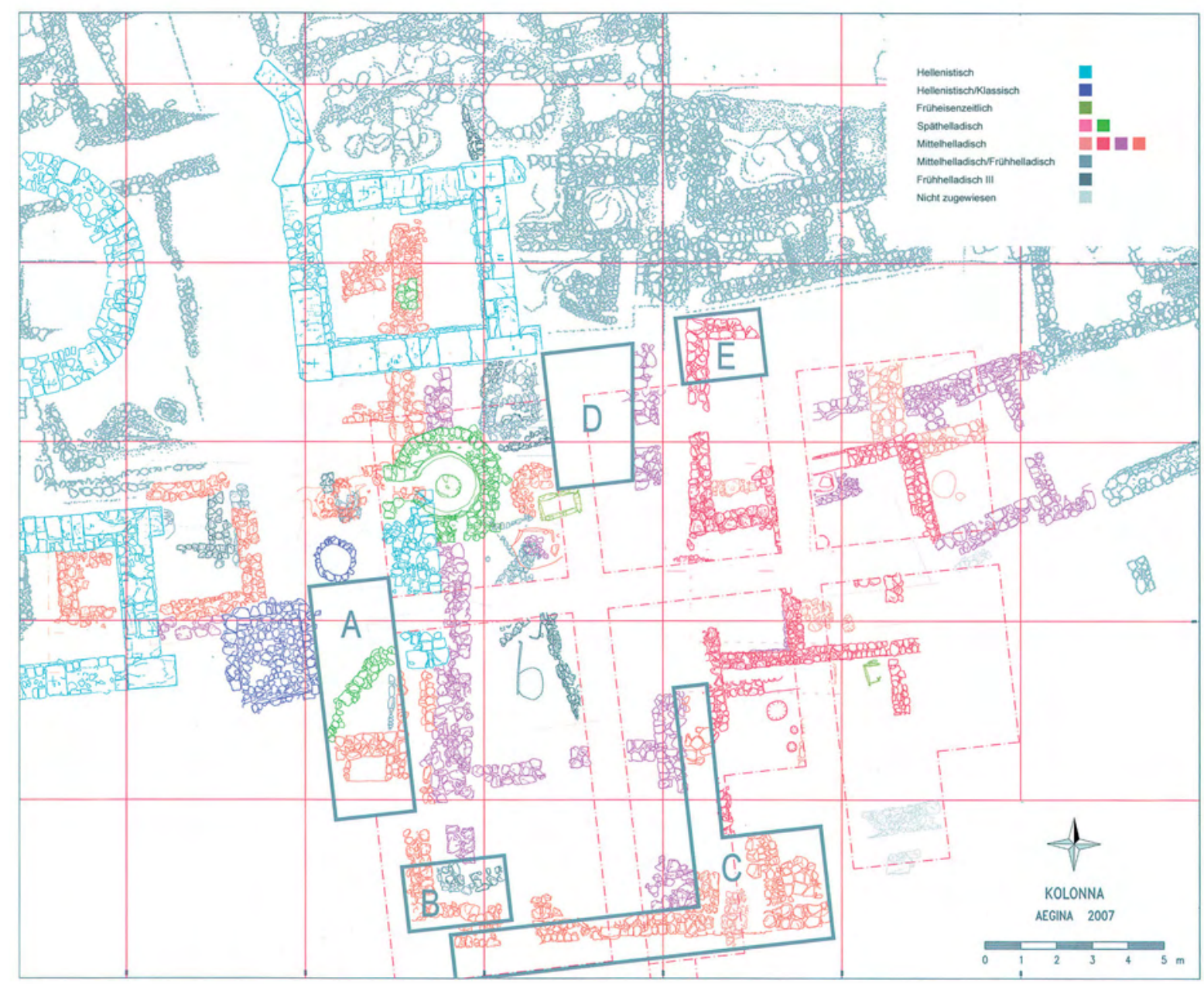

25 Phasenplan Areal Südhügel

Siedlung gestört, zudem reichte ein hellenistischer Bothros bis tief in die prähistorischen Schichten. Der Bothros, der bereits bei den Grabungen von 2002 teilweise ausgehoben worden war, wurde 2007 komplett geleert. Unter den Funden ist eine größere Zahl Fragmente hellenistischer Reliefbecher und Glanztonware mit Schlickerdekor hervorzuheben, ebenso wie gestempelte Amphorenhenkel (Abb. 26, 1-5) ${ }^{48}$. Einzelne qualitätsvolle früheisenzeitliche Gefäßreste (Abb. 26, 6) ${ }^{49}$ stehen vermutlich in Verbindung mit dem in unmittelbarer Nähe entdeckten protogeometrischen Kistengrab ${ }^{50}$.

Unter den obersten, teilweise gestörten Bereichen beginnt eine stratigraphische Abfolge, die von Späthelladisch I bis Mittelhelladisch III reicht. Zwei aufeinander folgende Fußbodenhorizonte wurden dabei freigelegt - eine stratigraphische Sequenz, die sich bereits bei den früheren Grabungen in Q6 und Q3 gezeigt hatte ${ }^{51}$. Der höhere Boden, der in SH I datiert wird, gehört zur dritten Bauphase des GSB. Auf ihm

${ }^{48}$ Abb. 26, 1-5: Q2/025-037; Q2/025-050; Q2/025-053; Q2/025-012; Q2/025-011; zu den Grabungen 2002 s. Felten u. a. (Anm. 1:2003) 58-59 Abb. 21.

49 Abb. 26, 6: Q2/027-012.

${ }^{50}$ s. Felten u. a. (Anm. 1:2003) 118-121 Abb. 25. 26; F. Felten, Aegina-Kolonna: The History of a Greek Acropolis, in: Felten Gauß - Smetana (Anm. 46) 23.

${ }^{51}$ s. Felten u. a. (Anm. 1:2003) 120-121; Felten u. a. (Anm. 1:2007) 114-115; W. Gauß - R. Smetana, Aegina Kolonna, the Ceramic Sequence of the SCIEM 2000 Project, in: Felten - Gauß - Smetana (Anm. 46$) 65 \mathrm{f}$. 


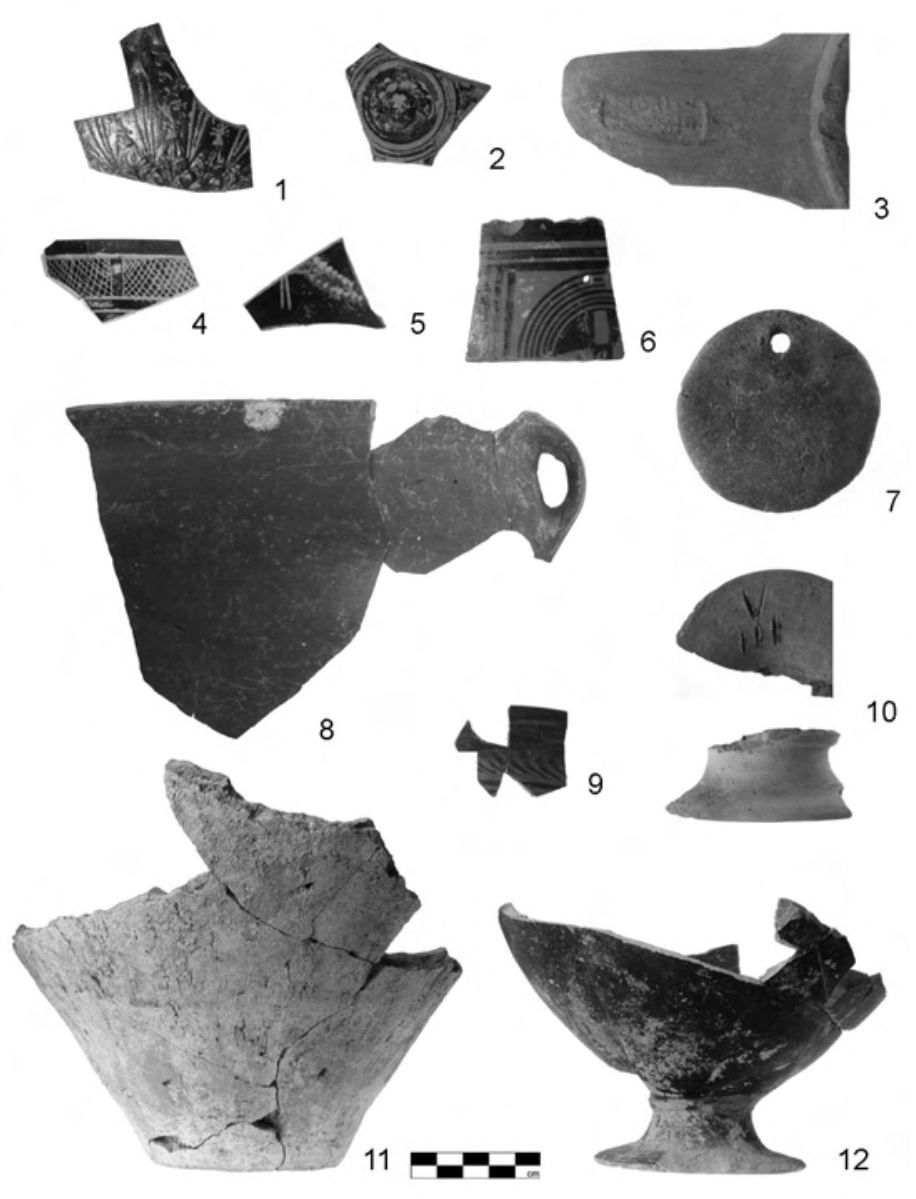

26

Q2. Hellenistische Gefäßfragmente aus dem Bothros (1-5), früheisenzeitliches Randfragment (6) sowie SH I-Funde (7-12)

stand der Unterteil eines äginetischen Kochtopfes, in dem Teile einer vollkommen bemalten äginetischen Goblet

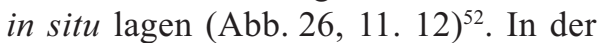
Auffüllung über dem Boden fanden sich u. a. größere Teile einer vollkommen bemalten äginetischen Goblet, äginetische unbemalte Keramik mit Töpferzeichen, ein lokal gefertigtes Webgewicht vom sog. minoischen Typ sowie die zerscherbten Fragmente eines bichrom (rot und weiß) bemalten, importierten Gefäßes (Abb. 26, 7-10) ${ }^{53}$. Wie bereits in den vergangenen Jahren beobachtet, folgte unter der Fußbodenschicht eine starke Füllschicht aus zerschlagenen Lehmziegeln und Steinen ${ }^{54}$. Im Gegensatz $\mathrm{zu}$ den bisherigen Beobachtungen enthielt die Füllschicht 2007 auch zahlreiche Funde, u. a. Scherben, aber auch eine Anzahl gut erhaltener Gefäße, von denen besonders eine äginetisch mattbemalte >panelled cup hervorzuheben ist (Abb. 27, 1-9) $)^{55}$. Die Füllschicht lag direkt auf einem weiteren, stellenweise stark verbrannten Fußboden auf, der zur zweiten Bauphase des GSB gehört ${ }^{56}$. Zwei Gefäße und eine vollständig erhaltene Lanzenspitze aus Bronze lagen

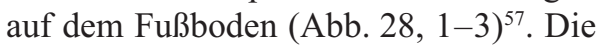
Lanzenspitze vom Typ Sesklo hat vier Nietlöcher und ein dreieckiges Fenster am Ende des Schaftschuhs, in dem noch

die Reste des Schäftungsholzes steckten ${ }^{58}$; die besten Vergleichsstücke kommen aus Kouphovouno (Lakonien), Sesklo (Thessalien), Nidri (Lefkas) und Vajzë (Albanien) ${ }^{59}$. Mit dem Erreichen des Fußbodenniveaus wurden die Grabungen in diesem Bereich von Q2 vorläufig eingestellt.

${ }^{52}$ Abb. 26, 11. 12: Q2/029-001; Q2/029-002.

${ }_{33}$ Abb. 26, 7-10: Q2/028-019; Q2/028-001; Q2/028-004; Q2/028-015.

${ }_{54} \mathrm{Zu}$ dieser Schicht auch Felten u. a. (Anm. 1:2003) 61; Felten u. a. (Anm. 1:2005) 32; Felten u. a. (Anm. 1:2007) 114.

${ }_{55}$ Abb. 27, 1-9: Q2/034-004; Q2/034-020; Q2/033-020; Q2/039-002; Q2/038-004; Q2/033-030; Q2/033-001; Q2/034-029; Q2/033-029.

${ }^{56}$ Die Westmauer der dritten Bauphase des GSB sitzt teilweise direkt auf dem Fußboden auf.

${ }^{57}$ Abb. 28, 1-3: Q2/034; Q2/036-001; Q2/036-002.

58 Aus dem Schachtgrab von Ägina stammt eine etwas ältere Lanzenspitze mit Schaftschuh. I. Kilian-Dirlmeier, Das mittelbronzezeitliche Schachtgrab von Ägina, Alt-Ägina 4, 3 (Mainz 1997) 23-27; C. Reinholdt, Entwicklung und Typologie mittelbronzezeitlicher Lanzenspitzen mit Schäftungsschuh in Griechenland, in: Mitteilungen der Berliner Gesellschaft für Anthropologie, Ethnologie und Urgeschichte 14, 1993, 43-52; O. Höckmann, Lanze und Speer im spätminoischen und mykenischen Griechenland, JbRGZM 27, 1980, 17-18. 131 Abb. 1, B4. B6

${ }^{59}$ Kouphovouno (Lakonien), MH-Grab: D. Blackman, Archaeological Reports for 2001-2002 (London 2002) 32 Abb. 59. I. KilianDirlmeier, Die bronzezeitlichen Gräber bei Nidri auf Leukas, Römisch Germanisches Zentralmuseum, Monographien 62 (Mainz 2005) 133 Anm. 506; Sesklo (Tessalien), Grab 56: Höckmann (Anm. 58) 15 Abb. 1, B4; 131, B4. Reinholdt (Anm. 58 ) 46 Kat. 10 Abb. 4 d. Kilian-Dirlmeier (Anm. 58) 24 Kat. 4; Nidri (Lefkas), Grab F7: Kilian-Dirlmeier a. O. Grab F7, Taf. 56, 2; 78. Reinholdt (Anm. 58) 45 Kat. 6 Abb. 3 e. Höckmann (Anm. 58) 15 Abb. 1, B6; 131, B6. Nach Kilian-Dirlmeier a. O. 133 ist die Lanzenspitze aus Nidri aus Kupfer und nicht aus Bronze; Vajzë (Albanien), Tumulus I, Grab 12: Reinholdt (Anm. 58) 45 Kat. 5 Abb. 3 d. 


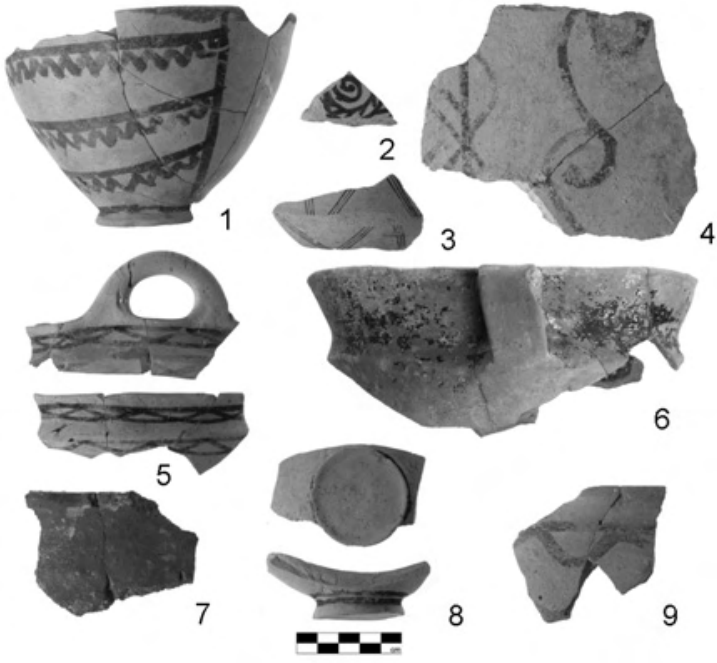

27 Q2. MH III-Keramik aus einer Füllschicht zwischen zwei Fußböden des GSB

Unmittelbar östlich des Hauptraumes des GSB wurde auf hohem Niveau ein schmaler Nord-Süd verlaufender Verbindungsweg gefunden. Noch ist unklar, ob es sich um einen Verbindungsweg innerhalb des GSB oder um die eigentliche Gebäudegrenze handelt. In der nach Osten angrenzenden Raumeinheit war bereits in den vergangenen Jahren gegraben worden (Abb. 25, Bereich E) ${ }^{60}$. Die obersten Schichten sind auch hier durch die spätrömisch-byzantinische Nutzung gestört. Unmittelbar darunter wurden die Reste eines Fußbodenhorizonts freigelegt, über dem die Teile weitgehend erhaltener Gefäße lagen (Abb. 28, 4) ${ }^{61}$.
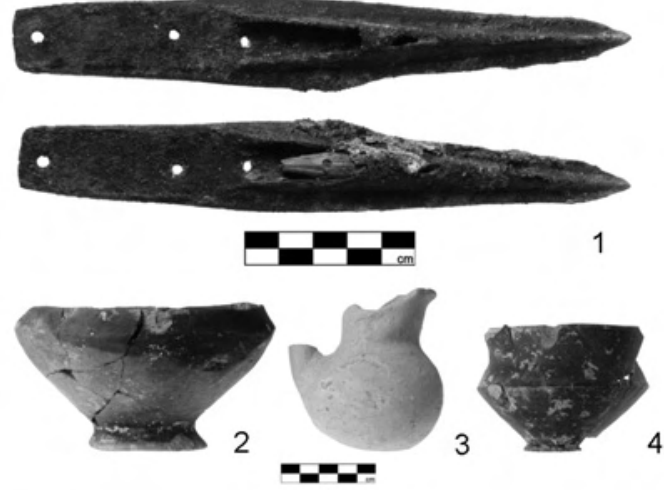

28 Q2. Bronzene Lanzenspitze und MH III-Gefäße vom Fußboden GSB, Phase 2

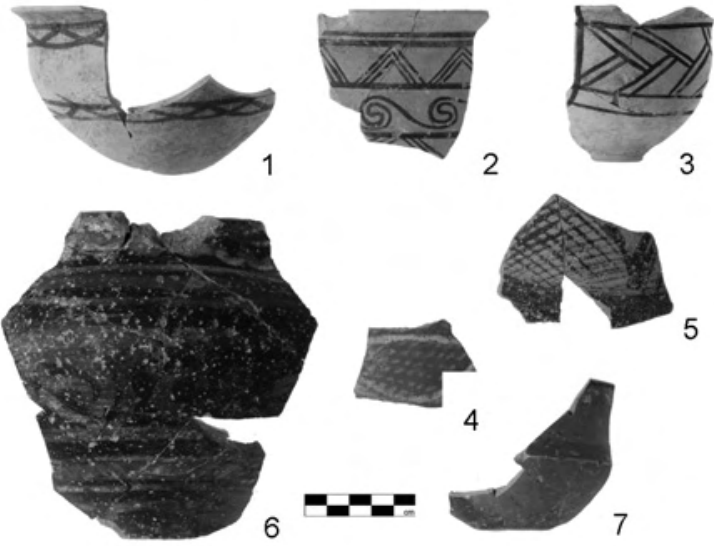

29 Q5. Äginetisch mattbemalte Keramik (1-3), >minoisierende bichrome Fragmente (4-6) und minoisches Knickwandgefäß (7)

\section{Quadrant Q5 - Nord-Süd verlaufender Weg (Abb. 25, Bereich C, nördlicher Teil)}

Die vorangegangenen Ausgrabungen und Untersuchungen in Q5 ergaben, dass der Hauptraum des GSB (Bauphase 3) im Osten durch die Nord-Süd orientierte Mauer 2002/62 begrenzt wird. Im Jahr 2006 wurde außerdem die südöstliche Mauerecke des GSB gefunden ${ }^{62}$. Die bisher vor allem an der Westseite des GSB erfolgten Beobachtungen ließen vermuten, dass die älteren Mauern des Hauptraumes um ungefähr eine Mauerbreite nach außen versetzt liegen, das ältere Gebäude bzw. der Hauptraum also etwas größer gewesen war. An der südlichen Schmalseite wird der GSB von einem Ost-West orientierten Weg begrenzt.

Die Arbeiten 2007 sollten den Mauerverlauf und die südöstliche Ecke der älteren Bauphasen aufdecken, die unmittelbar östlich von Mauer 2002/62 unter dem Nord-Süd verlaufenden Verbindungsweg (Abb. 30, 1: 2002/81) vermutet wurden (Abb. 25, Bereich C, nördlicher Teil). Die Grabungen im Bereich des Weges erbrachten ein hohes Fundaufkommen, vor allem Keramik und teilweise große Knochenteile, die Mauer

\footnotetext{
${ }^{60}$ s. Felten u. a. (Anm. 1: 2006) 29-30 Abb. 27-28.

${ }^{61}$ Abb. 28, 4: Q2/040-001.

62 s. Felten u. a. (Anm. 1:2007) 112.
} 


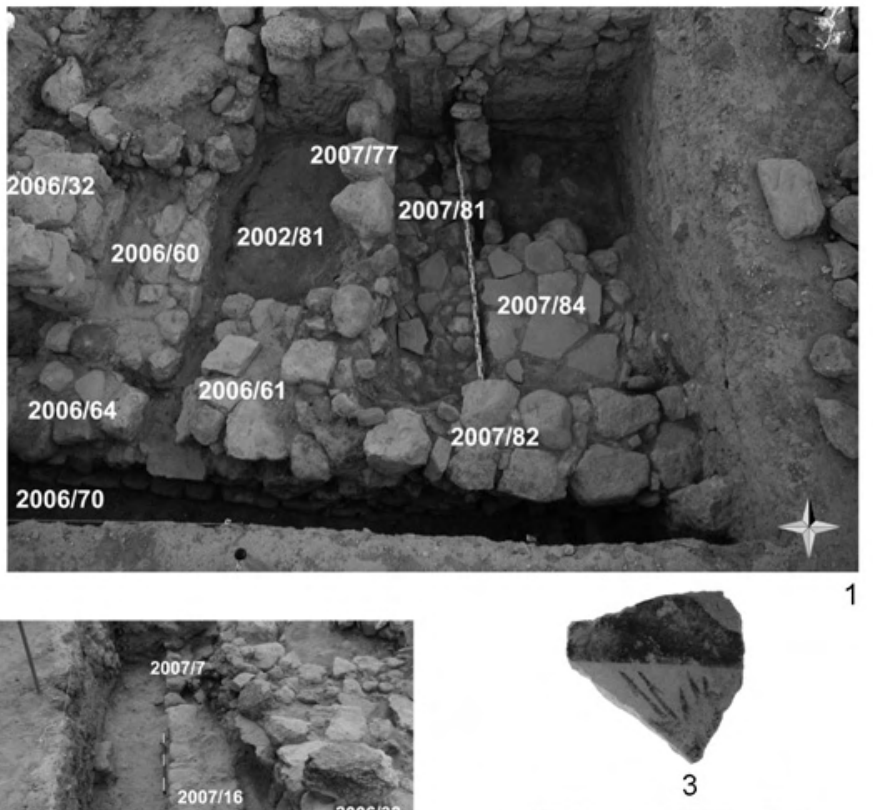

3
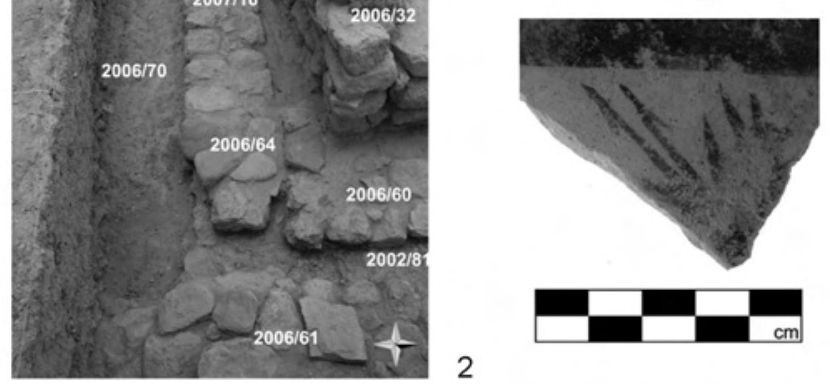

30 Q5 und Q6. Südostecke des GSB (1), Südbegrenzung (2) und Pithosscherbe mit figürlicher Darstellung (3) des Vorgängerbaus wurde jedoch nicht freigelegt $t^{63}$. Bei der Ausdehnung der Grabung nach Osten kamen die Reste weiterer mittelbronzezeitlicher Raumeinheiten zutage, allerdings ist gegenwärtig unklar, ob sie zum GSB gehören oder zu einem neuen Hauskomplex. Die Beurteilung des Grabungsbefundes wird durch die zahlreichen spätrömischen und byzantinischen Störungen und Mauerausrisse zusätzlich erschwert. Unabhängig von der Frage, ob die neu gefundenen Raumeinheiten zum GSB gehören oder nicht, konnte die Beobachtung gemacht werden, dass der Nord-Süd verlaufende Verbindungsweg ursprünglich breiter war und später teilweise aufgegeben und überbaut worden ist (Abb. 30,1). Die aus diesem Bereich stammende, qualitätsvolle Keramik (Abb. 29) ${ }^{64}$ ist insofern von Bedeutung, als bislang noch nicht bekannte Musterkombinationen der äginetischen Mattmalerei hier erstmals festgestellt wurden. $\mathrm{Zu}$ den besonders hervorzuhebenden Importen gehören das vollständige Profil eines minoischen Knickwandgefäßes (Abb. 29, 7) sowie das vollständige Profil eines offenen Gefäßes der sog. minoisierenden Keramik mit bichromer Hell-auf-Dunkel-Bemalung (Abb. 29, 6), außerdem Fragmente weiterer >minoisierender geschlossener

Gefäße (Abb. 29, 5). Der Nachweis eines offenen Gefäßes der sog. minoisierenden Keramik verdient besondere Beachtung, da bei den bisherigen Grabungen ausschließlich geschlossene Gefäßformen gefunden wurden $^{65}$.

Quadrant Q5, Q6 - Ost-West verlaufende Straße (Abb. 25, Bereich C, südlicher Teil)

Während der letzten Jahre wurden im südlichsten Teil von Q5 und Q6 Teile einer West-Ost orientierten Straße (Abb. 30, 2: 2006/70) freigelegt, in die der oben erwähnte Nord-Süd orientierte Verbindungsweg einmündet (s. Bereich D). 2007 wurden die Grabungen im Ost-West verlaufenden Weg fortgesetzt, mit dem Ziel, die südliche Begrenzung des GSB zu lokalisieren, vor allem die frühen Bauphasen (Abb. 30, 2). Der Weg besteht aus zahlreichen lockeren Kiesellagen, vermischt mit großen Mengen an Keramik und Tierkno-

\footnotetext{
${ }^{63}$ Auch im Jahr 2006 wurden Mengen an Keramik und Knochen im Bereich der Wege gefunden; s. Felten u. a. (Anm. 1:2007) 113.

${ }^{64}$ Abb. 29, 1-7: Q5/099-003; Q5/067-009; Q5/101-008; Q5/099-001; Q5/064-001; Q5/099-002; Q5/107-001.

${ }^{65}$ Zusammenfassend zur sog. minoisierenden Keramik und dem Versuch, die geographische Herkunft besser zu bestimmen s. E. Kiriatzi, >Minoanising` pottery traditions in southwest Aegean during the Middle Bronze Age: Understanding the social context of technological and consumption practice, in: Touchais (Anm. 46).
} 
chen $^{66}$. Die Keramik ist stark zerscherbt, bislang wurden nur wenige anpassende Teile gefunden. Besonders hervorzuheben ist das Wandfragment eines geschlossenen, äginetisch mattbemalten Gefäßes mit den Resten einer figürlichen Darstellung: Die mindestens fünf aufgerichteten Speere weisen auf Bewaffnete hin (Abb. 30, 3) ${ }^{67}$. Bedauerlicherweise ist der Erhaltungszustand nicht ausreichend, um die Szene zweifelsfrei zu erklären. Figürliche Darstellungen sind im Allgemeinen in der Mittleren Bronzezeit sehr selten, aus Ägina sind u. a. der sog. Schiffspithos, der sog. Schiffsreiter und Bewaffnete auf einem Schiff bekannt ${ }^{68}$. Die geneigten und offensichtlich nicht regelmäßig angeordneten Speere der neu gefundenen Darstellung könnten auf eine bewegte (Kampf?)Szene deuten.

Die kontinuierliche Nutzung und Aufhöhung des Ost-West verlaufenden Weges überdeckt dabei die Reste einer langen Ost-West verlaufenden Mauer (Abb. 30, 1. 2: 2007/7, 2007/16, 2006/64). Die Mauer liegt eine Mauerbreite vor der Südostecke des GSB (Phase 3) und erstreckt sich über die gesamte Breite des GSB-Hauptraumes und zumindest im Osten noch darüber hinaus. Das berechtigt zu der Vermutung, dass es sich hierbei um die südliche Begrenzungsmauer einer älteren Bauphase des GSB handelt. Ist dies zutreffend, dann ge-
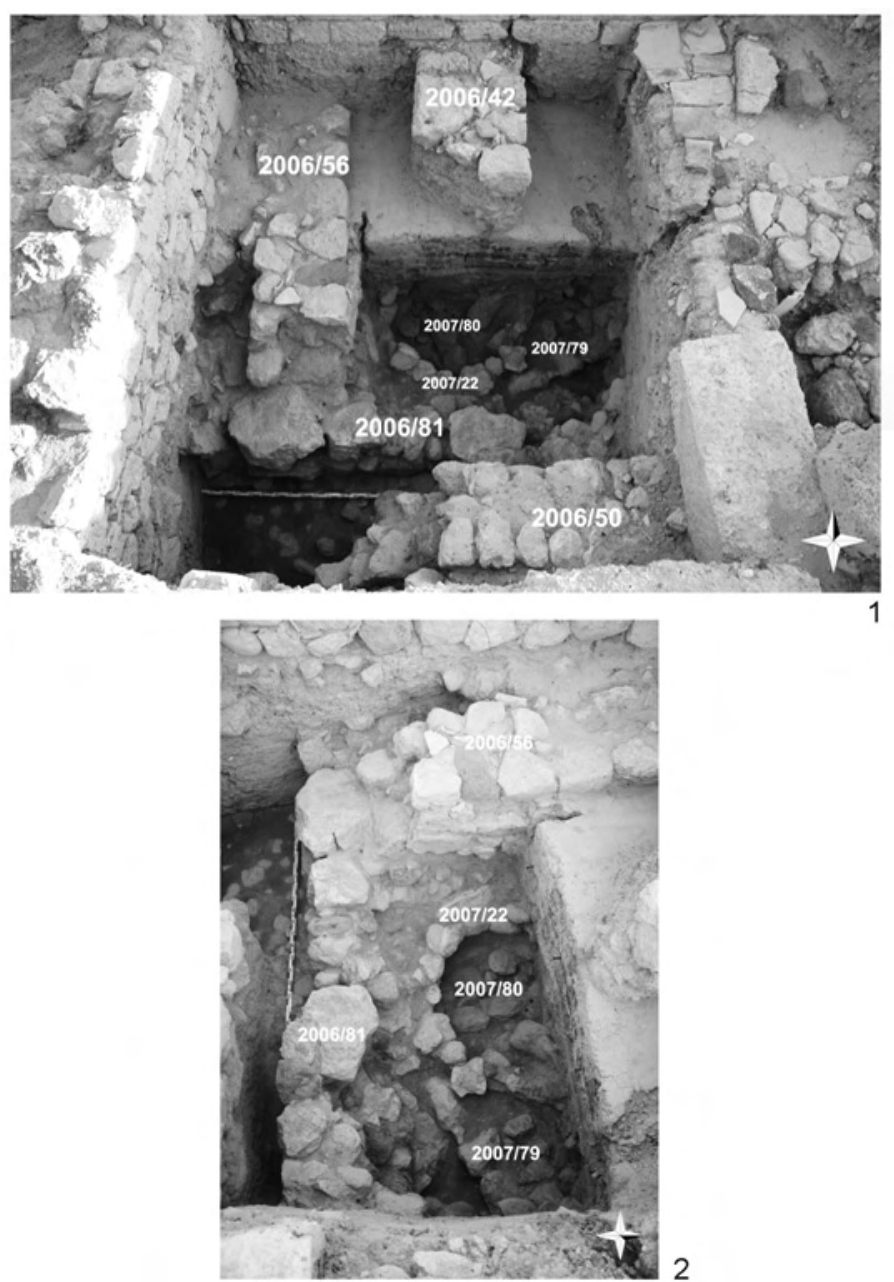

31 Q6. Südwestecke des GSB und FH III/MH-Mauern

hören die in Q5 neu gefundenen Raumeinheiten, die ebenfalls im Süden von dieser Mauer begrenzt werden, mit großer Wahrscheinlichkeit zum GSB. Problematisch ist, dass der Mauerverlauf im Bereich der Südwestecke des GSB stark gestört und die Einbindung der Ost-West-Mauer in die Nord-Süd-Mauer nicht erhalten ist (Abb. 31, 1). Auch der Mauerverlauf des jüngeren GSB (Phase 3) ist im Bereich der Südwestecke stark gestört. Die Nord-Süd verlaufende Mauer (2006/42) ist bereits vor der Südwestecke großflächig ausgerissen, und von der Ost-West verlaufenden Quermauer sind bislang nur sehr geringe Reste freigelegt worden ${ }^{69}$.

\section{Quadrant Q6 - Südwestecke des GSB (Abb. 25, Bereich B)}

Die Grabungen aus dem Jahr 2006 im Bereich der Südwestecke des GSB wurden fortgesetzt ${ }^{70}$. Wie erwähnt (s. o. Bereich C, südlicher Teil), ist der Bereich der Südwestecke durch die spätrömische und byzantinische

\footnotetext{
${ }^{66}$ Vgl. o. Anm. 63.

${ }^{67}$ Abb. 30, 3: Q6/166-003

${ }^{68}$ St. Hiller, Fisch oder Schiff, Pantheon 30, 1972, 439-446; H. B. Siedentopf, Mattbemalte Keramik der Mittleren Bronzezeit, Alt-Ägina 4, 2 (Mainz 1991) Taf. 14. 35-38.

${ }^{69}$ s. Felten u. a. (Anm. 1:2007) 115.

${ }^{70}$ s. Felten u. a. (Anm. 1:2007) 115.
} 

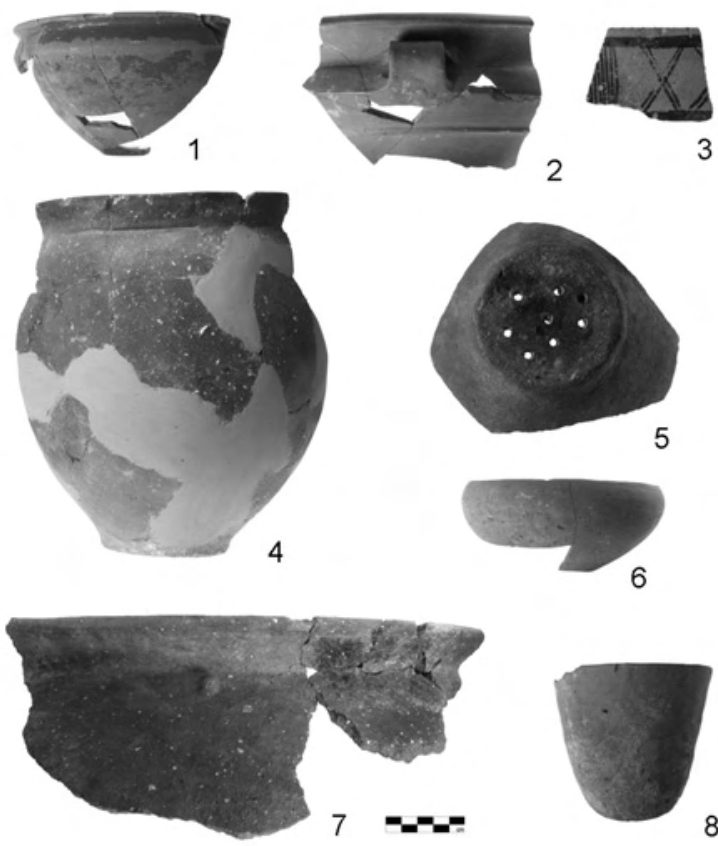

32 Q6. Keramik der Phase H (Siedlungsphase Kolonna VII/ VIII)
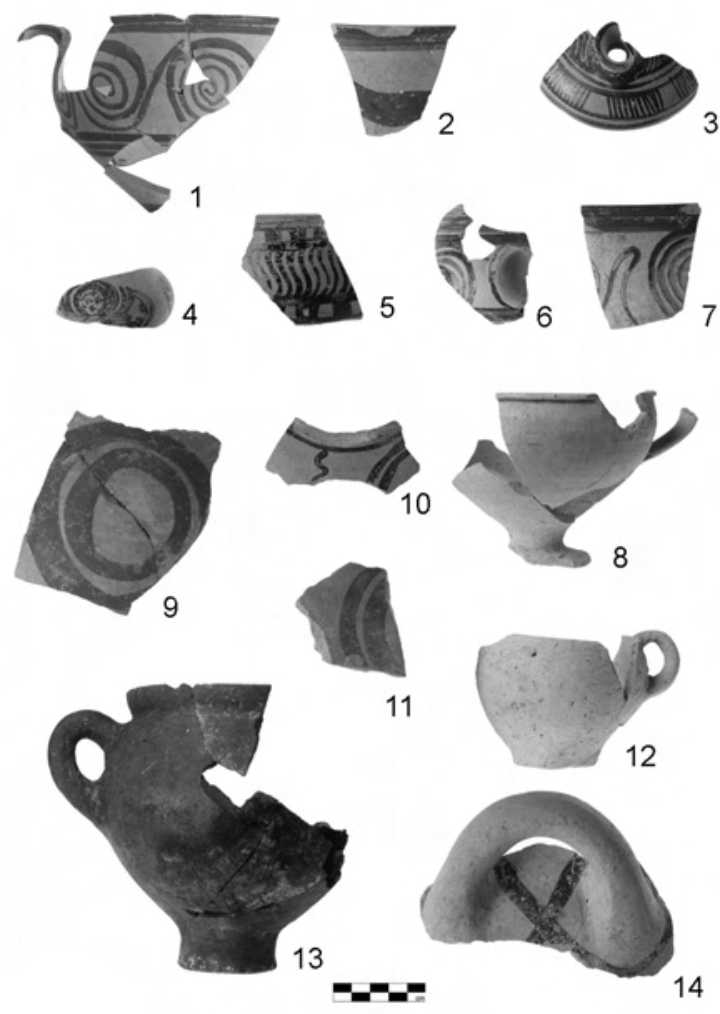

34

Q7. SH-Keramik aus dem Zugangsbereich des Töpferofens

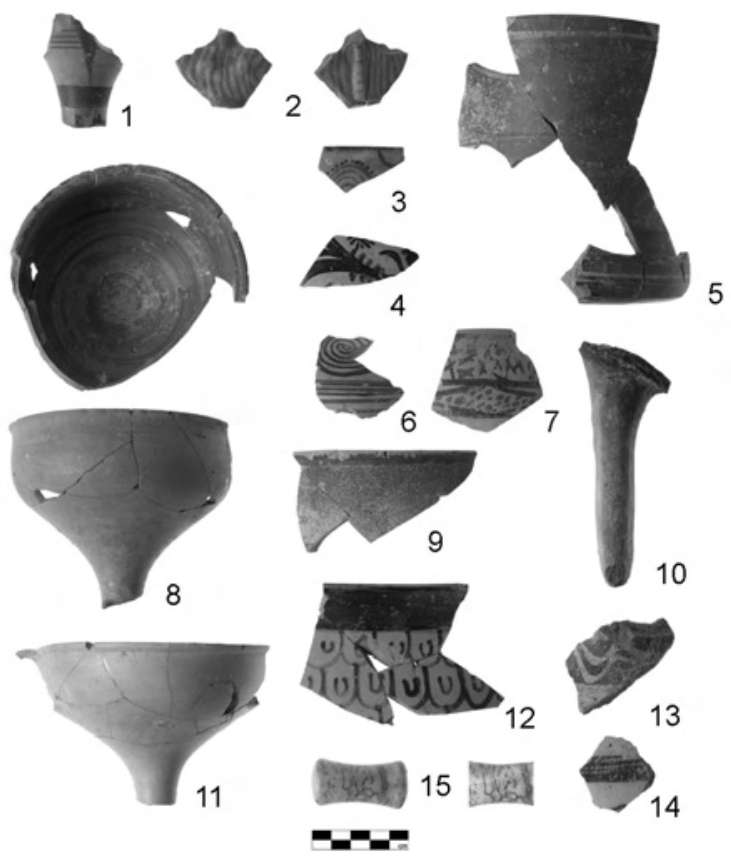

33 Q7. SH-Keramik aus dem Zugangsbereich des Töpferofens

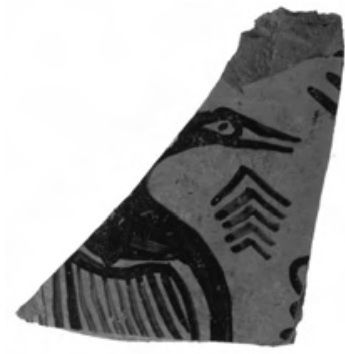

$\oplus$

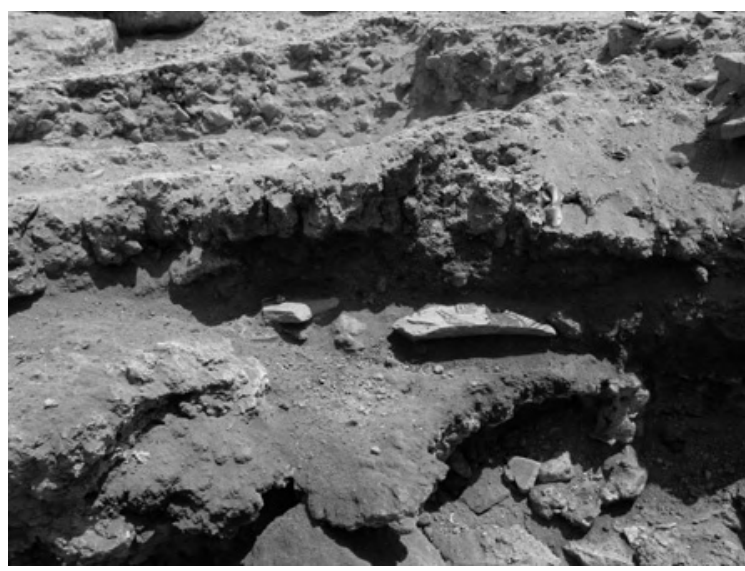

35 Q7. Aschenschichten mit Scherbe im >Pictorial Style 
Siedlung tief gestört, wodurch sämtliche prähistorischen Mauern teilweise ausgerissen sind. Im Jahr 2007 wurde an der Innenseite der GSB-Mauer 2006/56 (Abb. 31) eine ungestörte Abfolge ergraben, die Erkenntnisse zu den Anfängen des GSB erbrachte.

Nach dem gegenwärtigen Stand der Ergebnisse wurde der GSB am Beginn der Mittleren Bronzezeit direkt auf den Häusern der älteren Siedlung errichtet. $\mathrm{Zu}$ seiner ältesten Bauphase gehören wahrscheinlich ein Fußbodenhorizont und eine mit Steinen ausgekleidete Grube oder ein Bothros (Abb. 31: 2007/22). Die darin gefundene Keramik - u. a. Fragmente unbemalter Schüsseln mit einziehendem Rand, geradwandige Becher oder Vorratsgefäße - gehört in die keramische Phase H (Siedlungsphase Kolonna-Stadt VII/VIII) ${ }^{71}$ (Abb. 32) (2. $^{72}$

Direkt unter der Grube bzw. dem Bothros liegen die Reste einer älteren Mauerecke. Die beiden kurzen Mauerstücke (Abb. 31: 2007/79 und 2007/80) könnten aufgrund ihrer Orientierung zu Mauern gehören, die 2006 im zentralen Bereich von Q6 ergraben wurden ${ }^{73}$.

Quadrant Q7 (Abb. 25, Bereich A)

Im Grabungsabschnitt Q7 sollte die westliche Außenmauer des GSB der jüngeren und der älteren Bauphase sowie der Zugang zum mykenischen Töpferofen weiter freigelegt werden. Im Zuge der Arbeiten konnten stratigraphische Beobachtungen zur prähistorischen Nutzung gemacht werden. Die obersten Schichten waren durch den spätklassischen Altar ${ }^{74}$ und die spätrömisch-byzantinische Siedlung gestört. Hier wurde vor allem ein dichter Steinversturz festgestellt, vermengt mit mykenischer, aber auch spätrömischer und klassischer Keramik. In der Folge konzentrierte sich die Arbeit zunächst auf den nördlicheren Abschnitt, den Zugangsbereich um den Töpferofen.

\footnotetext{
${ }^{71}$ W. Gauß - R. Smetana, Aegina Kolonna, The Ceramic Sequence of the SCIEM 2000 Project, in: Felten - Gauß - Smetana (Anm. 46) 61-63.

72 Abb. 32, 1-8: Q6/164-005; Q6/164-001; Q6/164-004; Q6/164-006; Q6/177-003; Q6/177-005; Q6/177-006; Q6/178-001.

${ }^{73}$ s. Felten u. a. (Anm. 1:2007) 116.

${ }^{74}$ s. Felten u. a. (Anm. 1:2003) 57-58; Felten u. a. (Anm. 1:2004) 116 mit Anm. 36; Felten u. a. (Anm. 1:2005) 26.
} 
Zugangsbereich um den Töpferofen Im ungestörten Bereich wurden in der Folge von Norden nach Süden leicht abfallende Laufhorizonte freigelegt, die zum Töpferofen führen. Sie bestehen aus kieseliger und aschiger Erde, gefüllt mit Mengen an mykenischer Keramik und Tierknochen. Der größte Teil der Funde ist mykenische Keramik der Phase SH IIIA. Aber auch qualitätsvolle SH IIIB1-zeitliche Keramik fand sich, wie beispielsweise das Fragment einer Kylix (Abb. 33, $1)^{75}$. Einige der besten Stücke sind allerdings auch älter, teilweise sind sie mittelbronzezeitlich. Unter den Funden sind besonders die zahlreichen vollkommen bemalten, offenen Gefäße wie Kylikes und Goblets oder die äginetischen Kochtöpfe hervorzuheben (Abb. 33. 34) ${ }^{76}$. Lokal äginetisch mattbemalte Keramik wurde offensichtlich bis in SH IIIA erzeugt, allerdings beschränkt sich das Formenrepertoire bislang auf mittelgroße, geschlossene Gefäß ${ }^{77}$. Das Musterrepertoire ist gering, es drückt sich hauptsächlich in vertikalen Wellenbändern und mehrfachen Kreisen auf den Schulterzonen aus (Abb. 34, 9-11). Die Henkel werden von liegenden Achterschlingen umschlossen (Abb. 34, 14). Neben qualitätsvoller, musterbemalter mykenischer Keramik wurden die Fragmente einer zyprischen >milk bowl und eines südostägäischen Gefäßes in der charakteristischen Hell-auf-

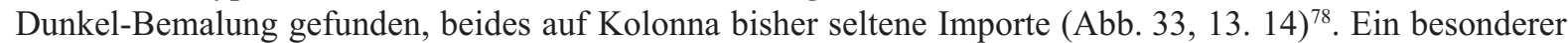
Einzelfund aus der Frühbronzezeit II wurde ebenfalls in den mykenischen Schichten gemacht: Es handelt sich um ein walzenförmiges Steingerät (Abb. 33, 15). Die jüngsten Arbeiten von L. Rahmstorf konnten nachweisen, dass es sich bei den walzenförmigen Steingeräten um frühbronzezeitliche Gewichte handelt, die im gesamten Ägäisraum verbreitet waren ${ }^{79}$. Mehrere dieser Gegenstände wurden in Ägina-Kolonna bereits gefunden, teilweise in FH II-Kontexten, aber auch in jüngeren Mittelbronze- und Spätbronzezeitschichten ${ }^{80}$. Das besondere an dem Neufund sind die drei vertikalen Ritzlinien an der Stelle des schmalsten Durchmes-

${ }^{75}$ Abb. 33, 1: Q7/011-001; vgl. etwa P. A. Mountjoy, Mycenaean Decorated Pottery, SIMA 73 (Göteborg 1986) 114 Abb. 141; 115 (FS 258B).

${ }_{76}$ Abb. 33, 1-15: Q7/011-001; Q7/011-017; Q7/009-003; Q7/011-002; Q7/01-001; Q7/022-017; Q7/011-003; Q7/04-004; Q7/027014; Q7/016-003; Q7/037-020; Q7/026-014; Q7/015-008; Q7/053-001; Q7/046-018. Abb. 34, 1-14: Q7/046-001; Q7/054-035; Q7/033-001; Q7/033-002; Q7/048-006; Q7/054-026; Q7/054-027; Q7/052-005; Q7/033-003; Q7/054-006; Q7/025-002; Q7/054085; Q7/054-093; Q7/054-005.

77 W. Gauß, Ägina Kolonna in frühmykenischer Zeit, in: E. Alram-Stern - G. Nightingale (Hrsg.), Keimelion. Elitenbildung und elitärer Konsum von der mykenischen Palastzeit bis zur homerischen Epoche. Akten des internationalen Kongresses vom 3. bis zum 5. Februar 2005, DenkschrWien 350 (Wien 2007) 163-172.

${ }^{78}$ Südostägäischer Import: N. Momigliano, Kamares or not Kamares? This Is (Not) the Question. Southeast Aegean Light-on-Dark (LOD) and Dark-on-Light (DOL) Pottery: Synchronisms, Production Centers and Distribution, in: Felten - Gauß - Smetana (Anm. 46) 269. Zyprische Keramik: Felten u. a. (Anm. 1:2003) 64. 65 Abb. 27, 4; F. Felten, Aegina Kolonna: The History of a Greek Acropolis, in: F. Felten - W: Gauß - R. Smetana (Hrsg.), Ägina-Kolonna. Forschungen und Ergebnisse I: Middle Helladic Pottery and Synchronisms (Wien 2007) 20 Abb. 14.

${ }^{79}$ L. Rahmstorf, Zur Ausbreitung vorderasiatischer Innovation in die frühbronzezeitliche Ägäis, PZ 81, 2006, 49-96 bes. 73-79; L. Rahmstorf, In Search of the Earliest Balance Weights, Scales and Weighing Systems from the East Mediterranean, the Near and Middle East in: Weights in Context, in: Proceedings of the International Colloquium Rome 22nd-24nd November 2004, Istituto Italiano di Numismatica. Studi e Materiali 13 (Roma 2006) 9-45; zur Ägäis s. bes. 24-28.

${ }^{80}$ Die bislang in Ägina-Kolonna gefundenen Steingeräte, einschließlich der bis 2006 am sog. Südhügel gefundenen, wurden von L. Rahmstorf dokumentiert und in den in Anm. 79 genannten Arbeiten berücksichtigt. Zu älteren Veröffentlichungen der Gewichte s. H. Walter - F. Felten, Die vorgeschichtliche Stadt, Alt-Ägina 3, 1 (Mainz 1981) Taf. 127; F. Lang, Artefakte aus Fels- 


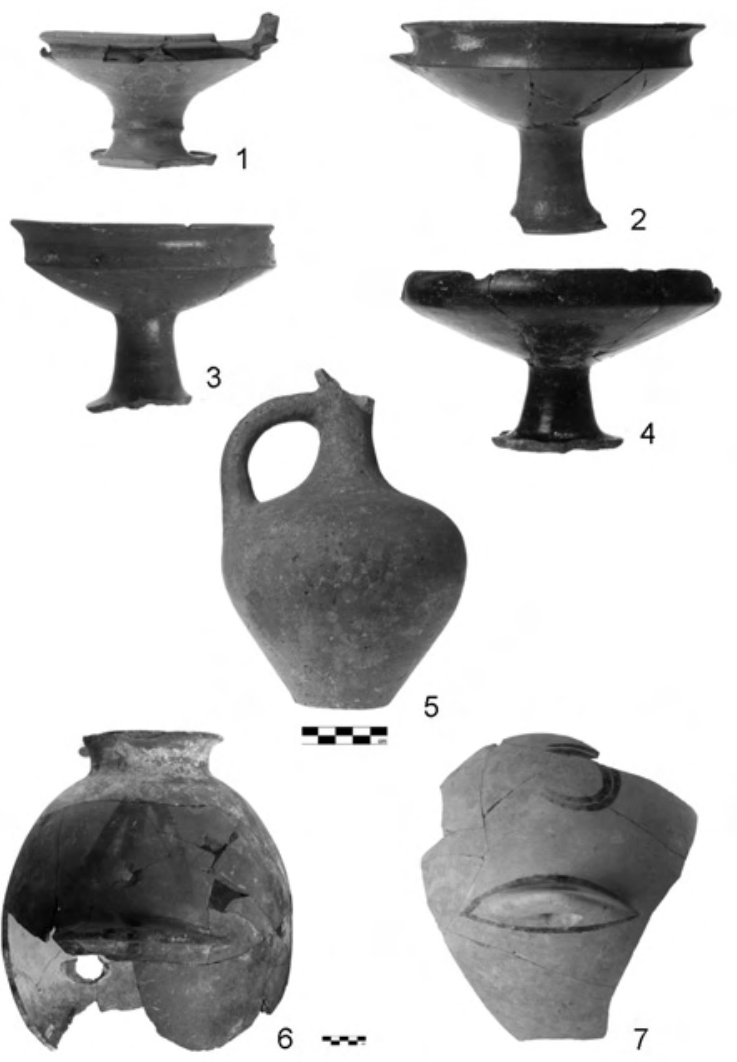

38 Q7. Mittelbronzezeitliche Gefäße aus (1-5) und neben dem Schacht (6-7)

sers, nach Rahmstorf Angaben zur Gewichtseinheit $^{81}$. Der Umstand, dass einige Gewichte in jüngeren Kontexten angetroffen wurden, wirft nach Rahmstorf auch die Frage auf, inwieweit die FH II-zeitlichen Gewichte in späterer Zeit als solche weiter verwendet wurden.

Ein Laufhorizont aus der letzten Nutzung des Töpferofens ist mit einer dicken und pulvrigen Aschenschicht bedeckt ${ }^{82}$. Die Masse der keramischen Funde stammt von äginetischer unbemalter Trink- und Kochtopfware, die teilweise zu vollständigen Profilen zusammengesetzt werden konnte. Besonders hervorzuheben ist das Randfragment eines offenen Gefäßes, das im sog. Pictorial Style mit einem Vogel verziert ist und direkt auf der Aschenschicht auflag (Abb. 35). Die wenigen Fragmente von >Pictorial style <-Keramik, die bislang in Kolonna gefunden wurden, hat inzwischen St. Hiller umfassend vorgelegt ${ }^{83}$; mehrheitlich stammen sie aus den Grabungen G. Welters und sind ohne Angaben zum Fundkontext.

\section{Der Großsteinbau}

Im südlicheren Grabungsbereich sind die Laufhorizonte, die zum Töpferofen führen, durch die spätere Nutzung teilweise gestört. Unter dem dicht gepackten Steinversturz wurde zunächst die Fortsetzung der Nord-Süd verlaufenden Mauer vom Hauptraum des GSB (Phase 3) festgestellt. Die Mauer der älteren Bauphasen (GSB 1 und 2, Mauer 2007/34) liegt, wie vermutet, um eine Mauerbreite nach außen versetzt auf etwas tieferem Niveau. Im Zuge der Ausgrabungen wurde außerdem klar, dass sich der ältere GSB weiter nach Westen erstreckte. Eine Reihe von Fußböden läuft von Westen her an die Mauer 2007/34 des Hauptraumes, ebenso wie ein kurzes Mauerstück (2007/31: Abb. 36, 2). Zur westlichen Fortsetzung des GSB gehört auch ein ca. $1 \mathrm{~m}$ langer und 0,6 m breiter Schacht, der von Mauern aus Lehmziegeln und Bruchsteinen gebildet wird. Der Schacht war mit Keramik der Mittleren Bronzezeit (Abb. 37) gefüllt: Bislang konnten fünf weitgehend vollständige Gefäße überwiegend kykladischer Herkunft zusammengesetzt werden; weitere Gefäße sind lokal äginetisch oder Importe vom griechischen Festland (Abb. 38) . $^{84}$.

gestein von den neuen Grabungen in Ägina-Kolonna, in: B. Asamer - W. Wohlmayr, Akten des 9. Österreichischen Archäologentages (Wien 2003) 129-134 Taf. 42.

${ }^{81} \mathrm{Zu}$ den bislang sehr seltenen Markierungen s. L. Rahmstorf, In Search of the Earliest Balance Weights, Scales and Weighing Systems from the East Mediterranean, the Near and Middle East in: Weights in Context, in: Proceedings of the International Colloquium Rome 22nd-24nd November 2004, Istituto Italiano di Numismatica. Studi e Materiali 13 (Roma 2006) 24 f.; L. Rahmstorf, Zur Ausbreitung vorderasiatischer Innovation in die frühbronzezeitliche Ägäis, PZ 81, 2006, 75. Für weitere Informationen zu den Gewichten danke ich L. Rahmstorf.

82 Dieselbe Schicht wurde bei den Grabungen 2004 und 2005 gefunden; s. Felten u. a. (Anm.1:2004) 122; Felten u. a. (Anm. 1:2005) $26-28$.

${ }^{83}$ Abb. 35: Q7/48-38. St. Hiller, Keramik mit Pictorial Style Dekor aus Ägina Kolonna, in: Figurative painting on Mycenaean and Geometric pottery. Pictorial pursuits (Stockholm 2006) 73-82. Zu dem >Pictorial Style « im Allgemeinen: E. Vermeule - V. Karageorghis, Mycenaean Pictorial Vase Painting (Cambridge, MA 1982). Ähnliche Vogeldarstellungen dort unter Kapitel VIII. »Middle Pictorial« (82-84 Taf. 8, 14. 16).

${ }^{84}$ Abb. 38, 1-7: Q7/041-001; Q7/041-004; Q7/041-005; Q7/041-006; Q7/041-009; Q7/043-026; Q7/043-027. 
Ähnlich wie in Q6 (Bereich B) wurden auch in diesem Abschnitt aufschlussreiche stratigraphische Beobachtungen zur Errichtung des GSB gemacht. Die Nord-Süd verlaufende Mauer der Phasen GSB 1 und 2 sitzt direkt auf einer älteren Mauer auf (Abb. 36: 2007/34, 2007/62), die mit der Spät-FH III-zeitlichen Siedlung bzw. der Siedlung am Übergang zur Mittelbronzezeit in Verbindung zu bringen ist.

\section{Zusammenfassung}

Die Ausgrabungen 2007 lieferten weitere Erkenntnisse zur Sonderstellung der Siedlung von Kolonna während der Bronzezeit. Im Zugangsbereich des Töpferofens wurde eine Fülle mykenischer Keramik gefunden. Von besonderer Bedeutung sind die mykenische Scherbe im >Pictorial Style und die zyprischen sowie südostägäischen Importe. Die lokal erzeugte mattbemalte Keramik lebte in einem eingeschränkten Formen- und Musterrepertoire bis in SH IIIA weiter.

Vor allem zur Bauabfolge und Ausdehnung des GSB konnten neue Ergebnisse gewonnen werden. Es ist dies das wichtigste Gebäude der Mittleren und beginnenden Späten Bronzezeit, das während seiner wahrscheinlich annähernd dreihundertjährigen Existenz mehrfach erweitert und umgebaut worden ist. Allerdings hat sich bislang die Hoffnung nicht erfüllt, den Grundriss der verschiedenen Bauphasen des GSB vollständig freizulegen. Die Grabungen von 2007 zeigten, dass der GSB komplexerer Struktur ist, als ursprünglich angenommen, und dass sich das Gebäude weiter nach Westen und Osten fortsetzt.

Unter den zahlreichen mittelbronzezeitlichen Einzelfunden sind besonders die komplett erhaltene bronzene Lanzenspitze mit Schäftungsschuh und eine Anzahl vollständiger Gefäße hervorzuheben, die auf einem spätmittelbronzezeitlichen Fußboden des GSB lagen. Zu einer älteren Phase des GSB gehören die im rechteckigen Schacht gefundenen, fast vollständigen Gefäße, die überwiegend kykladischer Herkunft sind. Aus der Ost-West verlaufenden Straße, welche den GSB an der Südseite begrenzt, stammt ein äginetisch mattbemaltes Fragment, das aufgerichtete Speere zeigt. Es dürfte sich um eine Darstellung bewaffneter Männer handeln, eine der seltenen figürlichen Szenen in der mittelbronzezeitlichen äginetischen Vasenmalerei.

Mit den Grabungen der kommenden Jahre sollen vor allem die noch offenen Fragen zur Ausdehnung der verschiedenen Bauphasen des GSB geklärt werden.

Prof. Dr. Florens Felten

Prof. Dr. Claus Reinholdt

Dr. Eduard Pollhammer

Dr. Rudolfine Smetana

Fachbereich Altertumswissenschaften/Klassische und Frühägäische Archäologie, Paris-Lodron-Universität Salzburg, Residenzplatz I/II, A-5020 Salzburg

E-Mail: vorname.nachname@sbg.ac.at

Dr. Walter Gauß

Österreichisches Archäologisches Institut, Zweigstelle Athen, Leoforos Alexandras 26, GR-10683 Athen

E-Mail: walter.gauss@otenet.gr

Abbildungsnachweis: Abb. 1. 9: Plan, Umzeichnung und digitales Layout E. Pollhammer; Abb. 2-7. 10-24: Photo M. Del-Negro, C. Reinholdt; Abb. 25: W. Gauß, H. Birk; Abb. 26-38: R. Smetana, W. Gauß, G. Klebinder-Gauß; digitale Bearbeitung und Layout: R. Smetana. Alle Abbildungen (C) FB Altertumswissenschaften, Klassische und Frühägäische Archäologie, Paris-Lodron-Universität Salzburg. 